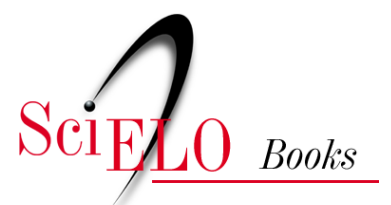

\title{
Análise estratégica hospitalar e projeto assistencial a perspectiva de Michel Crémadez e François Grateau
}

\author{
Francisco Javier Uribe Rivera
}

\section{SciELO Books / SciELO Livros / SciELO Libros}

RIVERA, F.J.U. Análise estratégica hospitalar e projeto assistencial: a perspectiva de Michel Crémadez e François Grateau. In: Análise estratégica em saúde e gestão pela escuta [online]. Rio de Janeiro: Editora FIOCRUZ, 2013, pp. 37-96. ISBN: 978-85-7541-303-6. https://doi.org/10.7476/9788575413036.0003.

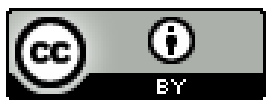

All the contents of this work, except where otherwise noted, is licensed under a Creative Commons Attribution 4.0 International license.

Todo o conteúdo deste trabalho, exceto quando houver ressalva, é publicado sob a licença Creative Commons Atribição 4.0. 


\section{Análise estratégica hospitalar e PROJETO ASSISTENCIAL: a perspectiva de Michel Crémadez e François Grateau}

Francisco Javier Uribe Rivera

A Démarche Stratégique representa, originalmente, o enfoque utilizado na definição da missão do Centro Hospitalar Regional Universitário (CHRU) de Lille, norte da França. Depois de uma visita a esta estrutura hospitalar, pude conhecer este importante instrumento de gerenciamento que, adaptado por nosso grupo ao Brasil, já foi aplicado em várias unidades hospitalares do Rio de Janeiro e divulgado pelo país. ${ }^{1}$

O termo démarche significa processo, trâmite, gestão, e poderíamos traduzilo como gestão estratégica. Nós nos propomos, neste capítulo, a apresentar, em grandes linhas, a proposta metodológica da Démarche Stratégique, bem como algumas de suas mais importantes referências teóricas.

A démarche é um método que supõe a adaptação de um enfoque empresarial ao setor público de serviços de saúde. Este enfoque de planejamento/gestão estratégica apóia-se em elementos da microeconomia, do campo da estratégia e da política, e da área do desenvolvimento organizacional e cultural. Introduz também algumas categorias próprias da área de saúde e da epidemiologia, reconhecendo a especificidade do setor público de saúde, na França. Está alicerçado em autores como H. Mintzberg (1982), Michel Crozier e Erhard Friedberg (1977), M. E. Porter (1982) e M. Thevenet (1986).

A partir de sua principal referência, a obra Le Management Stratégique Hospitalier, de M. Crémadez e François Grateau (1992; 1997), este enfoque propõe-se a

Destacam-se as experiências pioneiras no Hospital da Posse e no Hospital Phillipe Pinel e posteriormente nos hospitais da Lagoa, Cardoso Fontes, Raphael de Paula Souza e Lourenço Jorge, entre outras, mobilizando um grupo constituído pelo autor deste capítulo, por Elizabeth Artmann (Ensp/Fiocruz), Clayre Maria Bomfim Lopes (Nesc/UFRJ), Rejane Sobrino (Nesc/UFRJ) e Rosa Maria de Souza Souza (SES$\mathrm{RJ})$, entre outras. 
definir racionalmente a missão de um hospital, situando-o na perspectiva ideal de uma rede coordenada de serviços de saúde. Compreende-se, então, a organização hospitalar como uma organização pró-ativa, centrada sobre o exterior, que assume o ambiente como recurso e não como restrição. Isto significa que a definição da missão terá de ser negociada com o ambiente externo institucional, incluindo os outros hospitais da área à qual pertence. Desta maneira, destaca-se a capacidade pró-ativa da organização e sua atuação dinâmica sobre o ambiente.

As características das organizações sanitárias tendem naturalmente para um padrão que se distancia do ideal. Este ideal estaria representado pela aplicação de critérios de racionalidade econômica da missão, pela concepção do ambiente externo como recurso e por uma maior integração intrainstitucional. Contudo, o padrão apresentado pelas organizações de saúde e analisado com mais profundidade adiante tem alguns traços característicos: um processo de autonomização dos centros operacionais, decorrente de uma sorte de ruptura entre a direção estratégica e estes últimos, uma extrema diferenciação ou atomização das estruturas internas em função da especialização do trabalho, e uma desconsideração relativa da ambiência externa em razão de uma sobrevalorização corporativa do interno. Estas características dificultam a a possibilidade de um projeto gerencial que enfatize a integração intra-institucional, a racionalidade econômica da missão específica e a negociação de uma rede de cuidados com os outros estabelecimentos da ambiência imediata. A perspectiva da démarche é promover um tipo de movimento cultural que contrabalance essas tendências, abrindo caminho para o desenvolvimento de uma forma de organização que se aproxime daquelas premissas ideais (Rivera, 1997; Artmann, 2002).

Mais especificamente, os objetivos da démarche seriam:

- promover um elo de ligação entre a gerência estratégica e os centros assistenciais, por meio da comunicação;

- definir a missão do hospital de acordo com o critério de oportunidade. Isto equivale a determinar preferencialmente um padrão de atividades que permita vantagens comparativas, ao mesmo tempo que oferece um serviço de qualidade aos usuários;

- buscar um lugar de comunicação, onde os atores-serviços possam chegar a definir um projeto coletivo;

- favorecer a integração do hospital em uma rede de oferta de cuidados estruturada com a preocupação da eficácia e da eficiência;

- promover um processo de transformação cultural progressiva, não necessariamente preso à busca de objetivos instrumentais, imediatos.

Do ponto de vista da estratégia microeconômica, este enfoque questiona uma visão homogênea da excelência, representada pela intenção de firmar, na mesma 
escala; todas as áreas de atendimento. A alternativa a esta visão seria a de trabalhar a vocação de cada estabelecimento dentro da perspectiva da complementariedade. A melhor estratégia para que um estabelecimento possa obter vantagens comparativas é a diferenciação, que corresponde à definição de suas áreas de excelência, com o objetivo de priorizá-las, de expandi-las, negociando com a rede de serviços o atendimento das clientelas não incluídas nestas áreas (típicas de atividades de menor desenvolvimento relativo). A opção nuclear do enfoque é a idéia de procurar transformar a concorrência frontal em colaboração, buscando as competências distintivas de cada hospital e negociando as missões entre os diferentes estabelecimentos.

$\mathrm{Na}$ perspectiva político-organizacional, o enfoque se opõe a uma definição normativa e tecnocrática de diretrizes, apostando na via da responsabilização dos atores, que implica no desenvolvimento de processos comunicativos e de negociação internos e externos, que redundem em acordos relativos aos projetos assistenciais pertinentes a uma rede. Em relação à estrutura organizacional, o enfoque postula a necessidade de intensificar as estruturas em rede interna e o diálogo multidisciplinar, promovendo a busca de transversalidades.

Apresentaremos, a seguir, vários elementos da proposta geral de gestão estratégica de Crémadez, a partir de um resumo comentado de sua obra:

- as premissas gerais, de ordem teórico-conceitual, do enfoque;

- o método de análise estratégica da missão das especialidades médicas;

- $\quad$ as estratégias básicas de obtenção de vantagens comparativas;

- a proposta de estrutura organizacional em rede;

- a questão da padronização de processos de trabalho visando a organizar a diversidade;

- uma proposta geral de análise e planejamento da distribuição de recursos humanos.

\section{Premissas Teóricas Gerais do Enfoque de Crémadez}

\section{Dinâmica organizacional e prática decisional das organizações profissionais de saúde}

A partir de Mintzberg (1982), Crémadez e Grateau determinam, detalhadamente, as principais características de uma organização profissional:

- Primazia do centro operacional: engloba um grande número de unidades bastante independentes, altamente especializadas, que reconhecem um ambiente diferenciado. Significa que estas unidades são mais importantes 
do que outras estruturas/instâncias organizacionais, reunindo suficiente saber e autonomia para tomarem suas próprias decisões. Cada centro operacional se diferencia por ter as próprias normas, procedimentos, usuários diferenciados e por estar ligado a diferentes entidades ou sociedades de especialistas (sociedade de cardiologia, sociedade de oftalmologia, ortopedia, de cirurgiões etc.).

- Preponderância do relacional: o trabalho é coordenado por meio do ajustamento mútuo, que pressupõe relações espontâneas e informais entre responsáveis, e do processo de padronização das profissões, pois a formação profissional e a socialização em sociedades especializadas contribuem para a posse de um patrimônio comum de saber, métodos e comportamentos. Esta característica reforça a autonomia profissional e um fraco sentimento de pertinência à organização.

- Debilidade da tecnoestrutura: a tecnoestrutura tem um fraco poder de ingerência sobre os processos operacionais da organização, a não ser na dimensão econômica.

- A logística é importante: o tipo de coordenação respectiva é procedural e por resultados e se efetiva de maneira centralizada. A lógica diferente dos universos médico e logístico pode gerar problemas de coordenação. A expansão da importância dos meios logísticos tipicamente médicos, como equipamentos e tecnologias hospitalares, cria lutas de influência entre administradores e médicos, bem como conflitos dentro da própria comunidade médica.

- Ausência de linha hierárquica rígida: a direção não tem a capacidade nem a competência para dirigir diretamente os chefes dos vários serviços. Atua indiretamente através da tecnoestrutura e dos serviços funcionais e/ou de instâncias de negociação.

O resultado dinâmico desta caracterização é uma forte diferenciação (Lawrence \& Lorsch, 1973), com várias dimensões:

- Diferenciação entre o mundo administrativo e o mundo assistencial: o primeiro está mais voltado para as instâncias de regulação, persegue objetivos quantitativos e econômicos, inseridos em uma perspectiva política, articulando curto e longo prazos. Já o segundo busca objetivos mais qualitativos, ligados a uma perspectiva de mais curto prazo, representada pela demanda dos pacientes. Está centrado sobre tarefas particulares que requerem a mera aplicação de meios consagrados. Estas atividades são exercidas de maneira liberal e têm uma fraca pertinência organizacional. O nível hierárquico, neste segundo caso, está determinado pela competência. 
- Diferenciação entre logística e centro operacional: a logística é organizada de maneira mais mecanicista e coordenada segundo critérios econômicos, de forma centralizada. O mundo médico é descentralizado e organizado segundo o saber próprio e especializado. Há choques entre administração e centro operacional no que diz respeito ao controle dos equipamentos e das tecnologias médicas descentralizadas.

- Diferenciação no centro operacional: há uma forte especialização horizontal, bem como uma diferenciação no interior de cada serviço entre as várias categorias de profissionais e entre corpo médico e paramédico.

Para Crémadez, a diferenciação é fonte de eficácia. É necessário respeitar algum grau de diferenciação, valorizar as diferenças sem buscar a homogeneidade ou simetria. Deve-se, porém, compensar os efeitos negativos da diferenciação desenvolvendo formas de integração de uma força equivalente.

Como resultado de suas características estruturais e dinâmicas, a prática decisória das organizações profissionais é incrementalista: as decisões são tomadas em série, em função do poder de pressão momentâneo dos vários atores hospitalares, sem uma perspectiva de conjunto. Há uma justaposição de objetivos. Não se verifica, assim, o processo de formulação de uma estratégia anterior (ex-ante). Não se busca ou não se quer uma estratégia, esta seria o resultado emergente de decisões de natureza mais operacional, pontual. A estratégia emergente é o fruto de uma inflexão ou de um deslocamento discreto da estratégia anterior sob a influência de decisões sucessivas não geradas de forma global (Nioche, 1997).

Outros resultados da dinâmica organizacional dos estabelecimentos de saúde referem-se ao fechamento em relação ao exterior (ao ambiente) e um baixo sentimento de pertença à organização por parte dos profissionais médicos. $\mathrm{O}$ ambiente é percebido como um constrangimento e os que nele atuam adotam uma postura reativa. A organização está centrada sobre si mesma.

O processo de decisão estratégica procura inverter essas tendências. Objetiva ajudar a criar uma cultura em que o ambiente seja percebido como recurso; em que se antecipem as tendências do ambiente de modo a atuar criativamente sobre ele e onde a organização desenvolva sinergias e parcerias de modo a trabalhar dentro da premissa de redes de colaboração.

\section{A prática decisional da gestão estratégica}

A gestão estratégica rompe com a dissociação entre o estratégico e o operacional, buscando diluir essa divisão vertical. O poder de decidir sobre o aproveitamento de uma oportunidade está amplamente difundido pela organização e 
não mais concentrado na cúpula. A direção assinala as grandes orientações, os valores centrais do projeto organizacional, mas não define a estratégia propriamente dita, que depende da articulação de todos os atores organizacionais.

A gestão estratégica introduz um tipo de planejamento contínuo, flexível e ajustado, buscando concretizar um conjunto coerente de projetos. Traz à tona a questão dos objetivos por oposição a uma lógica de meios. É uma prática decisional mais integradora. Ao envolver o maior número de atores do centro operacional, procura reduzir ou, pelo menos, tornar transparente, o jogo político interno, por intermédio de vários fatores:

- A gestão estratégica teria a virtude da transparência representada pela utilização, no processo decisório, de dados objetivos sobre a atividade de base, e não de meras impressões de fundamentação relativa.

- A transparência estimula a comunicação desde a concepção das bases de coleta de informação, que pode cristalizar-se em uma nomenclatura comum de classificação e avaliação dos atos médicos, das patologias, modos de atendimento etc. O compartilhamento dessa informação contribuiria para uma harmonização da linguagem entre os atores de base da organização.

- É possível reconstituir, através do processo da segmentação estratégica, os diferentes domínios de atividade desmembrados pelo jogo da distribuição territorial do poder. As conseqüências desta transparência são várias: os diferentes atores da mesma unidade de base podem raciocinar a partir de uma visão mais clara e compartilhada de sua atividade, para prever sua evolução e conseqüências. A identificação, a partir da análise estratégica dessa segmentação, de domínios de atividades compartilhados permite explorar as sinergias, elaborar alternativas e estratégias comuns; a verificação de relações entre serviços permite estabelecer pontes entre os mesmos. Cria-se, ainda, uma interação permanente entre o mundo administrativo e o médico, pois o sistema de informações médicas e determinados tratamentos de dados passam a incorporar preocupações estratégicas, o que permite associar o raciocínio gerencial com o técnico.

- A gestão estratégica seria uma pedagogia de avaliação, na medida em que introduziria a preocupação com os resultados, para além de uma conduta pautada na aplicação de meios. A questão de como atender às expectativas dos usuários de uma rede estaria no centro de uma política de avaliação sistemática, como cultura a ser desenvolvida. O processo de avaliação estratégica se traduz, pela via da negociação, em projetos de ação, que se constituem em um estímulo à mudança, pois esse processo suscita uma inquietação natural em relação aos resultados possíveis.

- A gestão estratégica ajuda a formalizar as avaliações e os comentários que as justificam, gerando bases mais sólidas para dirimir litígios ou divergências 
de interpretação. A formalização é um elemento capital da comunicação e da coesão entre as diferentes categorias de profissionais.

- A gestão estratégica explora a diversidade, pois ensina a aceitar a possibilidade de abandonar a posse de uma tecnologia ou de um equipamento, quando não constituem competências distintivas de um serviço ou do hospital, e quando a eles se tem acesso através de sinergias e parcerias, de modo a se concentrar no estudo de formas alternativas de tipo de atendimento que podem valorizar o serviço e, ao mesmo tempo, ser úteis para os usuários.

- A gestão estratégica introduz o raciocínio dos custos de oportunidade ao levar em conta as necessidades dos outros e o grau de satisfação global obtido pela organização. A aplicação de um recurso a uma atividade deve ser justificada pelo maior ganho comparativo atingido relativamente a usos alternativos. As diferenciações, representadas pelo aprofundamento de competências distintivas, são estimuladas na medida em que se subordinam a uma perspectiva de maior eficiência e eficácia globais, considerando o sistema ou a rede.

- A gestão estratégica introduz a necessidade de estimular projetos que permitam a captação de recursos adicionais, o que pode ajudar a limitar conflitos de poder e a viabilização de projetos que, de outra forma, teriam de ser abandonados ou adiados.

A gestão estratégica pretende, assim, arbitrar pelos custos de oportunidade para criar uma solidariedade.

\section{A crise de identidade e a necessidade de renovar o contrato psicológico}

A identidade organizacional é um correlato francês do conceito de cultura. Este último englobaria as representações sociais compartilhadas sobre a organização e sua missão, dados sua história e seu papel na sociedade. O conceito de identidade acrescentaria, a esta visão integradora, uma dimensão oculta pela cultura: a dos jogos de poder dos atores e de seus mecanismos psíquicos. Considera-se cultura, nesta perspectiva, como "significante" da identidade e identidade, como algo que recupera a função ideológica das representações organizacionais e sua lógica de poder (Strategor, 1997). A identidade é um tipo de lógica coerente de uma organização, uma visão coletiva, partilhada, procedente de influências internas e externas. Ela se inspira em paradigmas e gera paradigmas que condicionam a vida dos indivíduos no interior da organização. Está na base de uma sorte de contrato psicológico entre cada indivíduo e a organização que define a natureza e a força de sua identificação com ela. 
A erosão de certos paradigmas tradicionais contribui para criar uma crise de identidade organizacional. O contrato psicológico que liga os indivíduos à organização se enfraquece como resultado do impacto da mudança de diversos paradigmas: o da Medicina, do serviço público e o paradigma profissional.

- A mudança do paradigma da Medicina: há uma especialização e concentração crescente de atividades e de meios tecnológicos em grandes estruturas hospitalares, que demanda, de forma crescente, uma intervenção do tipo gerencial. Diminui o estilo de exercício liberal da profissão e intensifica-se o controle administrativo dessas estruturas. Ao mesmo tempo que o trabalho médico se insere em estruturas burocráticas, a medicina passa a ser vista de uma nova perspectiva. Uma atuação médica eficaz passa a supor uma articulação entre a medicina orgânica/positivista e um enfoque ecológico ou ambiental. A oposição entre generalistas e especialistas perde sentido. O papel do médico agindo isoladamente vai sendo substituído pela atuação em equipe. As parcerias se tornam indispensáveis, assim como a concepção de novas formas de hospitalização. A busca por solidariedade entre os atores ocupa o centro das atenções.

- A mudança do paradigma do serviço público: a redução dos recursos leva ao questionamento acerca da possibilidades eqüitativas do serviço público, ou, como diríamos no Brasil, sobre seu caráter universal. Atender a todos igualitariamente passa a ferir o princípio da equidade, pois dificulta o acesso para determinadas camadas da população. Para muitos, o serviço público transformou-se na defesa de monopólios, atuando com excessiva independência (acarretando situações de arbítrio e de anonimato) e que tende a se reduzir, como conceito, a uma ideologia tecnocrática. Postula-se que o serviço público deve passar a aceitar a concorrência, a avaliação, a necessidade da escuta dos usuários, a abertura ao ambiente. Deve tornar-se internamente competitivo (racionalizando seus recursos) e trabalhar em rede. Privilegiam-se também a idéia da contratualização, bem como o estabelecimento de formas de cooperação e parcerias.

- A mudança do paradigma do profissional: a experiência deixa de ser a base essencial da competência profissional. A veloz renovação dos conhecimentos e das tecnologias torna obsoletos os recursos cognitivos anteriores. Isto provoca um crescimento da especialização e uma regressão da autonomia dos especialistas. A complexidade técnica crescente provoca uma interpenetração maior entre o técnico e o econômico. Diante desse quadro, a formação tradicional, mais artesanal, de acompanhamento de um profissional mais antigo, perde importância relativa. A formação e atualização permanente torna-se uma das chaves da competência profissional; a possibilidade de operar reorientações profissionais (mudança de especialidades) torna-se capital, tanto para o desempenho das carreira individual como para a eficiência organizacional. 
Os principais traços da identidade organizacional postos em questão seriam: a não explicitação dos projetos organizacionais, a justaposição de objetivos; o isolamento dos profissionais e dos serviços; a recusa à avaliação das competências; o corporativismo profissional; o estilo liberal de exercício profissional; a informalidade; a predominância dos critérios técnicos sobre os econômicos; a marginalização da gerência; a pouca preocupação com o ambiente externo, entre outros.

Essas mudanças criam uma crise de identidade, que acentua sentimentos e reações negativas, como a contestação dos médicos como grupo dominante, a recusa a escolher prioridades e o bloqueio de iniciativas, que substituem a vontade de empreendimento dos mesmos profissionais e a regulação de conflitos pelo crescimento. No plano externo, o hospital torna-se mais reativo, superestima restrições de recursos e passa a olhar o futuro com inquietação. Fazem parte do pano de fundo desta crise as necessidades de fortalecer a regulação administrativa e de introduzir critérios econômicos de gestão dos centros operacionais, o que ameaça a autonomia.

A gestão estratégica pretende operar movimentos que permitam a renovação do contrato psicológico entre os profissionais e a organização, em nossos dias bastante enfraquecidos. O impacto sobre a identidade organizacional compreenderia vários fatores:

- Ao formular um projeto de organização mais estruturado, com base na exploração de sinergias e de parcerias, a gestão estratégica busca colocar em evidência soluções (o que tem impactos psicológicos naturais) e escolher aquelas que permitem um maior ganho coletivo ao favorecer o compartilhamento de recursos. A gestão estratégica combina as estratégias individuais dentro de uma estratégia de conjunto, deslocando as atenções das atribuições para as contribuições. A formalização da informação, das análises e dos planos favorece a apreensão da organização por todos os atores. A instância reguladora (Ministério da Saúde) é convocada a decidir sobre objetivos explícitos e não somente sobre distribuição de recursos em estado de penúria. $\mathrm{O}$ próprio diretor do hospital fortalece sua posição ao ter de arbitrar, em última instância, o contexto de vários projetos médico-assistenciais.

- O processo de análise estratégica cria lugares de encontro, estimula a reflexão coletiva (intra e inter grupo profissional), distribui responsabilidades entre grupos, cria novas unidades, aumenta as interfaces externas. $\mathrm{O}$ sistema de poder, dividido e preso aos serviços, evolui para o estabelecimento de transversalidades e de interdependências. A natureza ao mesmo tempo técnica e econômica das decisões conduz à evolução das relações entre administradores e médicos no sentido da colaboração. Haveria mais integração e formalização. 
- O melhor conhecimento mútuo, com base na socialização de um sistema de informação, promove uma gestão negociada, que acentua a necessidade das sinergias e parcerias operacionais. O ambiente passa a ser o centro das atenções. Os vários agentes organizacionais passam a se visitar mutuamente, a conversar, a se encontrar mais. Os valores passam a ser questionados, trazidos à tona como fundamento das decisões. Determinados tabus como a competência alheia são relativizados. A avaliação estratégica justifica a necessidade de uma análise da competência global dos serviços em relação à capacidade de dar resposta aos usuários. A rigidez de posições corporativas cede lugar, em função da possibilidade do encontro, a posições mais flexíveis.

- O imaginário organizacional evolui, em síntese, para uma valorização da interdependências que compensa a reivindicação de autonomia, para uma apreciação positiva do sentido de bem coletivo da atividade. Os indivíduos se apropriam da organização com informação, formalização e análise e desenvolvem uma motivação para a ação. Sentem-se modelando e adaptando dinamicamente sua organização.

A renovação do contrato psicológico depende da mobilização de três alavancas:

- O papel da liderança: as situações de crise exigem a presença do poder de motivação do líder. Esta liderança deve anunciar a capacidade de assumir a iniciativa e de explorar novas regras do jogo. Deve comunicar com clareza, visando a fixar, focalizar progressivamente um novo modo de comportamento, guiado por um estado de espírito menos individualista, mais solidário, mais centrado na ação coletiva, que valorize as contribuições mútuas, a comunicação, que seja menos hierarquizado, menos prescritivo, mais aberto às expectativas externas, mais transparente. Esta liderança deve ajudar a projetar a imagem do sistema político não como um jogo de pressões aleatórias, mas como um processo de ação interativa consensual e contributiva.

- O papel da comunicação: a comunicação ajuda a criar uma linguagem comum e a integrar os discursos individuais em uma perspectiva global, de modo a aumentar a coesão social. A comunicação implica o reconhecimento do outro como legítimo outro, no reconhecimento das expectativas dos interlocutores, no reconhecimento da imagem que projetamos para os outros e na comparação entre essa imagem e o desejado. A comunicação exige uma releitura da organização para nos reconhecermos - como coletividade - no passado e para explorar determinados traços culturais que podem ser úteis para mudar, ou para identificar formas retardatárias de prática das quais podemos nos afastar positivamente. Comunicar nossa oferta de atividades é uma forma de fortalecer nossos compromissos diante dos demais integrantes da rede e de aumentar nosso nível de exigência. 
- A apropriação da organização pelos atores: sem uma apropriação da estratégia pelos atores, esta não irá em frente. Dada a característica processual, adaptável, nuançada, dos projetos dos vários serviços, torna-se necessário que os vários atores subscrevam uma carta de intenções estratégicas geral, que tenda a dar unidade às iniciativas locais, algo assim como o grande projeto de estabelecimento. Como entre o discurso e a real modificação de comportamentos há uma distância importante, é fundamental que se assuma a análise estratégica como um processo exploratório, iterativo e progressivo, como aprendizagem permanente.

\section{O modelo de mudança organizacional}

Este modelo de gerenciamento tenta articular a necessidade de racionalidade com a ampla participação dos atores da base organizacional. Opõe-se ao Modelo Racional de uma Ator Único (a direção), que busca apenas uma única solução ótima de natureza econômica, a partir de uma problemática que se pretende estruturada. Insere-se na perspectiva do Desenvolvimento Organizacional, que encara a mudança não como a gestão da passagem de um estado de equilíbrio para um estado de equilíbrio diferente, mas como a gestão do desequilíbrio que caracteriza toda organização dinâmica, desequilíbrio e movimento estando intimamente ligados. Na perspectiva do Desenvolvimento Organizacional, mudança e aprendizagem são fenômenos naturais e essenciais, de caráter permanente e não eventos induzidos ocasionalmente de fora. Esta perspectiva consiste em impedir a ingerência da hierarquia para que os atores organizacionais pesquisem os obstáculos ao bom funcionamento organizacional, que se identificam com freqüência com o comportamento interativo. Outra contribuição ao novo modelo de gerenciamento é a Análise Sociológica das Organizações, de Crozier (1977), que defende a necessidade de uma ampla participação para apoiar o processo de conquista do mundo exterior no potencial energético de atores autônomos que negociam um projeto solidário.

Este modelo é racional, pois acentua a necessidade de formular objetivos, pautados em uma raciocínio de custos de oportunidade e uma análise de tendências do ambiente exterior. É um modelo de negociação, participativo, de baixo para cima, que se apóia na formalização das análises, avaliações e estratégias e na utilização de um método de trabalho comum.

É um modelo propício à mudança, porque permite desde o início o encontro onde não havia encontro. 
Algumas características deste modelo:

- O processo supera o modelo: a coerência é fruto de ajustamentos sucessivos, de uma aprendizagem progressiva sobre a possibilidade de objetivos comuns, mesmo que parciais. Neste processo de aprendizagem, destaca-se a preocupação com a necessidade de uma atuação permanente sobre um ambiente complexo e evolutivo, de maneira não reativa.

- A organização é o produto das orientações: a organização se constrói a partir de planos de ação definidos coletivamente e de uma política de sinergias.

- As orientações provêm da base: em uma organização diversificada e achatada, a definição centralizada da estratégia é necessariamente redutora.

$\mathrm{Na}$ promoção do processo de mudança duas questões são vitais para Crémadez: em primeiro lugar, a necessidade de investimento pedagógico expressivo no território da metodologia, e de que os atores incorporem a idéia de que poderão manter o controle sobre o processo, dependendo os resultados de suas possibilidades; em segundo lugar, a necessidade de obter resultados rápidos e de que se consolide a idéia de que o distanciamento crítico em relação às competências profissionais ajudará a desbloquear situações inextricáveis.

Alguns princípios são muito importantes neste processo: ser transparente e argumentativo no processo de busca incessante do consenso, evitando apostar no antagonismo para contornar situações de impasse; evitar condutas de exclusão, mantendo a porta sempre aberta à discussão; explorar o poder de sensibilização do diretor, o qual deve explicitar com clareza sua vontade de mudança e assinalar as grandes linhas teóricas deste processo, considerando a satisfação dos usuários, a realização dos atores internos e um maior alcance da missão; dar-se o tempo necessário, considerando as particularidades de cada serviço e hospital, para que aconteçam processos de mudança; apostar na obtenção de resultados concretos para reforçar a crença na mudança no imaginário dos atores; fugir de um jogo em que um ator ganha e o outro perde, através da exploração das sinergias e parcerias, da socialização de meios; tornar os processos decisórios mais rápidos e combater a burocracia, para dar sinais evidentes de uma menor inércia organizacional.

Garantir uma viabilidade de permanência e continuidade para mudança dependeria de três fatores: a transferência da metodologia para os atores internos, com a substituição progressiva dos consultores externos; a evolução progressiva da tecnoestrutura; e o investimento em formação. 


\section{O Método}

As fases do método e seu conteúdo geral são:

- A análise do existente: corresponde ao diagnóstico do método.

- A segmentação: esta etapa corresponde à definição dos principais agrupamentos homogêneos de atividades, considerados aqueles que apresentam uma mesma problemática estratégica.

- A análise do valor e da posição competitiva de cada um dos segmentos resultantes dos agrupamentos de atividades: o valor corresponde ao interesse relativo ou ao nível de prioridade relativo que os segmentos teriam para a especialidade em função de uma política geral e depende do interesse na alocação de recursos. Um critério genérico na aferição desse valor está representado pela capacidade potencial de atração de clientela ofertando um atendimento de excelência, com eficiência; a posição competitiva é avaliada considerando-se o grau de controle sobre os chamados fatores-chave de sucesso (FCS), que corresponderiam a vantagens ou situações positivas necessárias para se ter êxito em uma atividade.

- A construção do porta-fólio de atividades, visando à definição da estratégia geral de atuação ou dos objetivos: o porta-fólio é um gráfico cuja abscissa está representada pela posição competitiva do estabelecimento e cuja ordenada representa-se pela capacidade de atração (valor) dos segmentos.

- O Plano de Ação, visando a atingir os objetivos a partir das estratégias, definidas em termos de três possibilidades: priorizar o desenvolvimento de um segmento; estabilizá-lo; reduzir o recrutamento de clientela ou recortar o segmento.

- A montagem dos indicadores de monitoramento do plano.

Vejamos o conteúdo mais específico de cada fase.

\section{A análise do existente}

O diagnóstico é administrativo e médico.

O diagnóstico administrativo é do tipo tradicional, com informações como: tempo médio de permanência, número de ingressos, pessoal médico e paramédico, estrutura física, perfil da demanda etc.

O diagnóstico médico compreende:

- relação de patologias atendidas por disciplina médica, ordenadas de acordo com uma complexidade crescente; 
- relação de tecnologias utilizadas por disciplina, ordenadas de acordo com a complexidade;

- cruzamento entre patologias e tecnologias, identificando-se a incidência das tecnologias sobre as patologias;

- relação das modalidades de atenção, considerando-se quatro critérios:

- se as atividades visando às patologias são ou não programáveis ou eletivas;

- se a intervenção sobre as patologias demanda consulta ambulatorial e/ ou hospitalização;

- o tipo de hospitalização requerida: o tempo da internação requerida;

- se as patologias listadas demandam um tipo particular de capacidade diagnóstica ou de exploração funcional (plateau tecnique) existente no serviço ou fora dele.

A fase diagnóstica inclui ainda a relação dos concorrentes e dos parceiros, bem como o desenho da rede de cuidados.

A rede de cuidados é um quadro que pretende levantar as atividades por segmento, divididas em atividades de diagnóstico, tratamento e acompanhamento, realizadas no serviço, em outros serviços do mesmo hospital e na rede (interfaces externas). (Ver Figura 1).

Figura 1 - Rede de cuidados (quadro adaptado) - (filière de soins).

\begin{tabular}{|l|l|l|l|}
\cline { 2 - 4 } \multicolumn{1}{c|}{} & Diagnóstico & Tratamento & Acompanhamento \\
\hline Serviço & & & \\
\hline Hospital (outros serviços) & & & \\
\hline Rede (interfaces externas) & & & \\
\hline
\end{tabular}

Fonte: UAS-CHRU, 1995.

O quadro Rede de Cuidados é um instrumento que possibilita identificar superposições e complementaridades eventuais entre os três níveis de serviços referidos, possibilidades de concorrência e também carências de atividades. 
O objetivo maior desta fase diagnóstica é proporcionar elementos para a fase seguinte, que consiste em segmentar os serviços segundo uma lógica que veremos a seguir.

\section{A segmentação estratégica}

A segmentação implica definir coletivamente, no nível de cada serviço, agrupamentos homogêneos de atividades, definidos como aqueles pólos de atividades em que predomina a identidade de elementos do ponto de vista de sua problemática estratégica. Neste processo, devem-se reduzir ao mínimo possível os fatores de discrepância. Caso se notem grandes diferenças, devem-se realizar novas divisões de categorias.

O objetivo central da definição de segmentos homogêneos é criar categorias que permitam uma análise estratégica representativa, tendo em vista que o hospital é uma instituição multiproduto, onde nem sempre todos os grupos de atividades apresentam o mesmo desenvolvimento ou o mesmo valor estratégico. Considera-se, então, que cada segmento reconhece um ambiente concorrencial específico.

A fase da segmentação é uma análise multicritérios, em que as diferentes atividades são submetidas ao crivo de vários critérios específicos:

- As patologias apresentadas pelos pacientes: tipo e localização da afecção; grau de complexidade; imbricações entre patologias.

- As características do processo de atendimento: necessidade de internação convencional ou específica (leitos de isolamento), grau de programação ou de eletividade da atividade.

- As características das tecnologias utilizadas: necessidade de dispor de uma estrutura técnica (de apoio diagnóstico, terapêutico ou de acompanhamento) específica; tamanho do investimento realizado ou a ser realizado; acesso à estrutura técnica geral.

- As competências necessárias: grau de sofisticação dentro da especialidade; multidisciplinaridade (recurso às competências de diversos especialistas).

- A concorrência: número de instituições e de profissionais que exercem a atividade e meios disponíveis.

- Tipo de população envolvida: idade, sexo, categoria sócio-profissional específica, ativo ou inativo.

- O lugar da atividade na rede de cuidados: urgência, diagnóstico, atenção, acompanhamento, educação sanitária, prevenção. 
Podem-se reunir estes critérios em quatro grupos:

- as patologias (enfarte, insuficiência cardíaca, arritmias etc., na cardiologia);

- as tecnologias (radiologia, ultra-som, laser etc.);

- os modos de atenção (internação convencional, consulta ambulatorial, hospital-dia etc.);

- população (alcoólatras, idosos, crianças, mulheres, entre outros).

Pode ser interessante uma análise progressiva, começando pelos critérios médicos patologia e tecnologia, mas busca-se criar agrupamentos homogêneos do ponto de vista dos quatro critérios, e não de um em particular. A definição é situacional, tendo em vista que os envolvidos podem privilegiar um determinado critério ou dois. Em geral, priorizam-se, de acordo com a experiência, os critérios médicos. Não se trata de descobrir uma estrutura universal e geral, que serviria de referência para organizações que oferecem atividades análogas, como se organiza e recorta o campo de uma disciplina científica. A definição dos segmentos está influenciada estrategicamente pela necessidade de apresentar, desde o início, os conjuntos de atividades típicos de cada hospital que contribuem para sua diferenciação. A forma como as atividades são organizadas previamente em função de uma dada cultura também é determinante de recortes particulares. A subjetividade é inerente à segmentação na medida em que esta depende do olhar que os interessados dirigem sobre suas atividades e o ambiente externo específico, condicionado pela identidade cultural da organização.

Cada um destes quatro ângulos de aproximação destaca, em maior ou menor medida, a dimensão médica, organizacional ou social da atividades. Assim, se os dois primeiros são estritamente de ordem médica, o terceiro (processo de atendimento) trata do contexto organizacional oferecido aos pacientes, ao passo que o quarto (população) está mais centrado nas necessidades de uma categoria específica de indivíduos. A escolha respectiva traduz escolhas estratégicas diferentes em termos da pesquisa de vantagens competitivas:

- Um segmento centrado nas patologias traduz a adoção de uma posição ampla na rede de cuidados, correspondendo a uma oferta diversificada e a processos de atenção variados (consultas, explorações funcionais, cuidados, acompanhamentos etc.).

- Um segmento centrado na tecnologia prioriza uma oferta específica correspondente a uma posição mais restrita e mais pontual na oferta de cuidados, seja no nível do diagnóstico, seja no nível curativo, ou no de acompanhamento (técnica particular de reeducação, por exemplo). Em geral, escolhese um segmento tecnológico quando se trata de técnicas e equipamentos de uma certa complexidade, de uso não indiscriminado, que englobam um 
conjunto característico de patologias e que constituem vantagens comparativas ou "exclusividades".

- Um segmento centrado em um modo de atenção privilegia o contexto dentro do qual se encontra o paciente e destaca a resposta a certas necessidades ou constrangimentos a partir dos quais ele pode julgar se os serviços que lhe são oferecidos (urgência, programação, duração...) estão adaptados às suas necessidades.

- Um segmento centrado em uma população específica de pacientes privilegia as expectativas ou as necessidades de ordem sanitária, mas também de ordem social, de um grupo de indivíduos aos quais podemos oferecer um serviço diferenciado, adaptado à sua especificidade.

O destaque dado a uma dimensão, patologia, por exemplo, não exclui, de maneira alguma, as outras dimensões: tecnologia, população, modo de atenção, que podem apresentar-se de maneira subordinada. Estes critérios não predominantes complementariam a descrição das características dos segmentos e ajudariam a refletir sobre o aspecto das sinergias. Em uma instituição, podem-se adotar, ao mesmo tempo, segmentos estratégicos que obedecem a critérios predominantes diferentes.

A segmentação estratégica é um método que permite apreender uma realidade complexa e decompô-la em subconjuntos mais simples de entender. Para constituir estes subconjuntos, privilegiam-se certos fatores comuns às atividades que os compõem, subordinando os fatores que as diferenciam. Assim, constrói- se um modelo redutor da realidade. A segmentação estratégica apresenta um risco importante se perdermos de vista as simplificações que ela oportuniza. Os segmentos não são estanques, tendo interfaces que devem ser estudadas. A identificação de problemáticas transversais é, então, indissociável da segmentação. Isto permite dar uma coerência de conjunto às atividades segmentadas anteriormente.

Quando o ponto de partida da segmentação é a estrutura organizacional, fica evidente a presença de relações entre os serviços, ligações freqüentemente escamoteadas pela dinâmica e diferenciação organizacional ou sacrificadas no altar da preservação dos territórios. As problemáticas transversais estariam geralmente ligadas:

- a oportunidades de colaboração entre disciplinas completamente afastadas no passado (por exemplo, o estudo do sono pode progredir através da associação de competências da pneumologia, da neurologia e da psiquiatria).

- à desestabilização, por inovações tecnológicas, de fronteiras classicamente reconhecidas, que provoca com freqüência guerras de apropriação (por exemplo, entre a endoscopia e a radiologia intervencionista). 
- à colocação em evidência de dependências mútuas no seio de uma mesma rede de cuidados (entre a cirurgia e a medicina para o diagnóstico e depois para o acompanhamento de certas formas de câncer ou de transplante, por exemplo).

- à evidência de necessidades comuns a várias disciplinas diferentes (avaliação dos desafios da nutrição, por exemplo).

O tratamento das problemáticas transversais pode-se traduzir, seja por uma nova segmentação: remodelagem do conteúdo dos segmentos existentes, aparecimento de novos segmentos (exemplo: o vascular, em cardiologia), seja pela delimitação de novos campos de sinergias (exemplo: entre o segmento vascular da cardiologia e o da neurologia).

A sinergia é o excedente de eficácia ou eficiência resultante da operacionalização conjunta de duas ou mais atividades ou segmentos distintos. A identificação das sinergias é fundamental sobre o plano estratégico, pois permite dar, mais uma vez, uma unidade ao conjunto dos segmentos reunidos em uma mesma organização. As sinergias definem as linhas de força da colaboração a se instaurar entre os diferentes componentes da organização, ou seja, a aplicação em comum dos recursos a fim de que a gestão das interfaces entre os segmentos seja fonte de vantagens competitivas. Se a detecção das sinergias é de ordem estratégica, a mobilização das mesmas pode ser também de ordem organizacional, através da adaptação das estruturas no sentido amplo, principalmente através da mobilização de estruturas de integração.

É importante assinalar que o processo de segmentação nunca é definitivo ou fixo e não se prende ao pré-existente, havendo a possibilidade de surgimento de segmentos virtuais. Durante este processo, novas e interessantes formas de segmentar podem surgir. Assim, uma segmentação iniciada através do predomínio do critério patologia pode mostrar-se extremamente extensa e pouco operacional e evoluir posteriormente para uma segmentação prioritariamente por tipo de atendimento, com a inclusão subordinada dos critérios tecnologia e população. As áreas de diferenciação estratégica de um hospital podem mudar ao longo do tempo, condicionando novas formas de segmentação que devem ser tratadas como um processo de aproximações sucessivas. Este processo é iterativo, progressivo e exploratório.

Daremos aqui alguns exemplos:

Segmentos do Hospital Psiquiátrico Philippe Pinel-SMS-Rio de Janeiro

- Ambulatório de Adultos

- Centro de Orientação Infanto-Juvenil (COIJ)

- Cais (Hospital-Dia de Adultos)

- Núcleo de Assistência Integral à Criança Autista e Psicótica (Naicap-Hospital-Dia de crianças) 
- Enfermarias A + B (psicóticos/pacientes graves)

- Unidade de Tratamento de Alcoolistas (UTA)

- Recepção e Emergência

- Laboratório (especializado em psiquiatria)

- Serviço de Imagem Cerebral

Esta segmentação está baseada fundamentalmente no critério tipo ou modo de atendimento, embora se apresentem recortes referentes a outros critérios, como, população (adulto/criança), patologia (UTA) e tecnologia (Serviço de Imagem Cerebral).

Segmentos da Cardiologia do Hospital da Lagoa-SMS-Rio de Janeiro

- Doença Arterial Coronariana (DAC)

- Arritmias

- Síncopes

- Cardiopatias Congênitas

- Hemodinâmica Intervencionista

- Hipertensão Arterial

- Cardiomiopatias

Esta segmentação é clássica, predominando amplamente o critério patologia, com a presença subordinada do critério tecnologia - hemodinâmica - , que reúne atividades que incidem sobre algumas das patologias que definiram segmentos (configurando uma superposição).

\section{Análise do valor de cada segmento}

A determinação do valor implica analisar cada segmento segundo vários critérios/subcritérios, dos quais destacamos:

- $\quad$ estado atual e perspectivas do mercado;

- barreiras à entrada de novos concorrentes;

- sinergias;

- $\quad$ grau de motivação interna;

- oportunidades do ambiente;

- $\quad$ potencialidades do segmento.

O objetivo central da análise do valor é hierarquizar os segmentos por meio de uma ponderação de critérios e de uma notação relativa. 
Cada critério geral teria um peso determinado, em termos percentuais, na fixação do valor do segmento (assim como os subcritérios específicos). Este peso é variável, situacional e referente à especialidade escolhida, ainda que esta ponderação relativa possa variar, para uma mesma especialidade, no caso de hospitais diferentes. Contudo, o peso expresso em percentuais permanece uniforme para a especialidade do hospital em foco, bem como para todos os seus segmentos. Esta ponderação corresponderia à importância relativa que cada critério teria para a comunidade de profissionais envolvida na análise estratégica segundo a aplicabilidade relativa dos critérios. Definido o peso relativo de cada critério, procede-se a um sistema de notação, atribuindo-se uma nota de 0 (zero) a 20 (vinte) por critério a cada segmento analisado. Esta nota consensuada corresponderia a uma visão prospectiva de como cada segmento se comportaria em relação a cada critério. Isto é, qual seria o nível de sinergia potencial? Quais as perspectivas de que cresça ou se desenvolva? Que potencial de captação de clientela e de desenvolvimento de pesquisa e de ensino é possível estabelecer? etc. O valor global do segmento será aferido em função das notas por critério e de seu peso específico, chegando-se a um score específico por segmento.

Passaremos a discutir brevemente o conteúdo destes critérios, à luz do material colhido em Lille, França, na UAS-CRHU (1995 a e b), bem como a partir da adaptação feita para a realidade brasileira (ver Anexo).

Em relação ao mercado, consideram-se as perspectivas de desenvolvimento, o risco de flutuação e a intensidade da concorrência.

As perspectivas de desenvolvimento referem-se à possibilidade de crescimento futuro dos segmentos de uma especialidade, considerando-se o cenário epidemiológico-social e o cenário tecnológico. Deve-se considerar que a evolução das técnicas de diagnóstico e de terapia podem contribuir para aumentar ou diminuir a demanda de serviços.

É importante a análise do risco de flutuação das técnicas que refere-se à previsão da emergência de novas técnicas capazes de modificar sensivelmente a atividade a curto ou médio prazo.

A intensidade da concorrência corresponde à previsão do quantitativo de instituições e de profissionais realizando a mesma atividade e a sua expressão em termos do controle dos meios necessários à oferta da atividade em questão.

Inicialmente, uma alta expectativa de crescimento induzida pelos fenômenos epidemiológicos e tecnológicos, uma previsão de estabilidade na evolução das técnicas e a presença de poucos concorrentes contribuiriam para valorizar o segmento, ao garantir, em tese, mais mercado para a especialidade de um hospital. Mas esta análise pode ser relativizada, dependendo do contexto sanitário, social e político da região onde se encontra o hospital. 
Em relação às barreiras de entrada de novos concorrentes no mercado, considera-se fundamentalmente o montante do investimento envolvido no desenvolvimento dos segmentos e as possibilidades de ser rentável ou obsoleto. Um investimento elevado já realizado e a previsão de continuidade valorizam o segmento em uma situação específica, pois isto significa vantagens comparativas em relação a outras organizações que não tenham realizado o mesmo investimento - que pode ser visto como barreira à entrada no mercado.

Pode-se desdobrar este investimento em equipamentos e tecnologia, capacidade instalada, recursos humanos especializados etc. Pode-se, também, considerá-lo de maneira agregada, com prioridade para o componente tecnológico.

As sinergias referem-se à possibilidade de compartilhar equipamentos, tecnologias, capacidade instalada, apoio logístico, bem como a opinião especializada dos profissionais. Este critério é importante tanto do ponto de vista da economia de custos quanto da qualidade dos serviços. Considera-se também que o sinergismo com outros segmentos e especialidades de um mesmo hospital e o potencial de parceria com a rede são fatores que incentivam o surgimento de um mercado ou de clientela, valorizando, portanto, o segmento.

Deve-se avaliar o grau de motivação interna pela disposição do corpo profissional de uma especialidade em investir nos vários segmentos. Esta é uma variável de conteúdo subjetivo relacionada ao grau de interesse que as atividades comportam em função do status das mesmas, de sua complexidade e da particular formação e cultura dos médicos.

As oportunidades do ambiente incluem a possibilidade de trazer recursos externos desenvolvendo cada segmento, de melhorar a imagem externa da especialidade e do hospital, o interesse manifesto das autoridades sanitárias revelado pela disposição de outorgar financiamentos suplementares, bem como o potencial de inovação decorrente da possibilidade de transferência de determinadas tecnologias.

As potencialidades dos segmentos corresponderiam à capacidade de atração de clientela regional e local, assim como às de geração de atividades de ensino e de pesquisa.

A atribuição de uma nota ao segmento por (sub)critério está baseada na formulação de perguntas-chave. Por exemplo, a avaliação das perspectivas de desenvolvimento supõe as perguntas:

A atividade em questão irá progredir nos próximos anos?

- $\quad$ em função dos fatores de risco (idade, por exemplo) ou

- $\quad$ em função da evolução tecnológica ou do savoir-faire (novas terapêuticas)?

Uma nota alta corresponderia à previsão de um forte crescimento e uma nota baixa, à estimativa de uma diminuição importante. 
Apresentamos, a seguir, a matriz básica adaptada do quadro de aferição de valor (Figura 2).

Figura 2 - Matriz de avaliação do valor dos segmentos de especialidade.

Especialidade/Disciplina:

Segmento:

Avaliação do Valor do Segmento:

\begin{tabular}{|l|l|l|l|}
\hline \multicolumn{1}{|c|}{ Critérios de avaliação } & $\begin{array}{c}\text { Peso } \\
\%\end{array}$ & $\begin{array}{c}\text { Nota } \\
\text { (de 0 a 20) }\end{array}$ & $\begin{array}{c}\text { Score } \\
(=\mathrm{p} \mathrm{x} \mathrm{n})\end{array}$ \\
\hline Mercado & & & \\
\hline $\begin{array}{l}\text { • Crescimento } \\
\text { - Insco de flutuação }\end{array}$ & & & \\
\hline Valon ponderade concorrencial & & & \\
\hline Barreiras à entrada & & & \\
\hline Sinergias & & & \\
\hline Grau de motivação interna & & & \\
\hline Oportunidades do ambiente & & & \\
\hline Potencialidades do segmento & & & \\
\hline Valor do segmento & 100 & & \\
\hline
\end{tabular}

Fonte: Crémadez \& Grateau, 1992.

Em nossa experiência, a análise do valor é considerada segundo os seguintes critérios: possibilidades de crescimento; intensidade da concorrência; tamanho do investimento, como barreira à entrada; potencial de sinergias (internas ao hospital), potencial de parcerias externas; potencial local e potencial regional de captação de clientela; motivação interna; potencial de ensino e de pesquisa; contribuição para o projeto político ou para a grande missão do hospital; contribuição para a imagem externa. Estes critérios comportam subcritérios explicitados durante a aplicação do enfoque para tornar o cálculo mais fácil.

O resultado desta fase é uma descrição precisa da problemática específica do segmento. Este método, apesar de não partir da categoria problema, permite, nesta fase, ir ao encontro dos problemas específicos. Por exemplo: 
- muitos concorrentes identificados resultam em uma nota fraca no tocante à intensidade da concorrência, o que contribui para um valor de mercado relativamente menor;

- expectativa de poucos aportes externos compromete o item oportunidades do ambiente;

- o fraco desenvolvimento da pesquisa pode comprometer as potencialidades de desenvolvimento geral.

Para que os critérios anteriormente aludidos não sejam fundamentalmente bases de investigação, mas de avaliação, é necessário submetê-los a um processo de formalização rigoroso. Assim, a avaliação do valor deve ser realizada sobre bases idênticas para todos os segmentos de atividade que compõem um estabelecimento. Caso contrário, a avaliação não poderá mais resultar em escolhas estratégicas, pois a elaboração de cada uma das grades específicas estaria apoiada em valores e modos de apreensão do meio ambiente diferentes, o que impediria toda comparação significativa.

A formalização da grade de avaliação deve evitar ao máximo os riscos de interpretações divergentes. Assim, o título do critério deve acompanhar-se de uma definição precisa do conteúdo do critério, da maneira de avaliar (significado positivo da variação) e do modo de cotação que será utilizado. Freqüentemente o grau de maturidade da organização face à avaliação definirá a utilização de uma cotação numérica. A vantagem de uma cotação numérica é permitir ponderar os diferentes critérios e obter uma nota global mais facilmente.

Apesar de todas as precauções que se possam tomar, a indisponibilidade de certos dados, bem como o fato de que, em certos casos, os especialistas consultados estejam implicados na cotação fazem com que não se possa evitar uma boa dose de subjetividade. A única maneira de minimizar esta questão é fazer com que a cotação se efetue em um contexto de participação suficientemente amplo para que haja a necessidade de se obter um consenso.

\section{A Avaliação dos fatores-chave de sucesso e da posição competitiva}

A análise da posição competitiva ou estratégica do hospital corresponde à identificação dos fatores-chave de sucesso (FCS) e ao grau de controle relativo por parte do hospital. Os FCS servem para avaliar a capacidade do hospital para obter bons resultados em cada um dos segmentos de atividade, ou seja, para satisfazer a demanda do serviço correspondente em qualidade e quantidade. 
Os FCS correspondem às competências/tecnologias que se devem controlar para se ter êxito nas atividades em análise. A identificação destes fatores-chave é equivalente à definição situacional de elementos de capacidade discriminante, ou seja, de capacidades específicas de ordem relacional, tecnológica, financeira ou de competências, cujo controle garante posições de vanguarda.

Este conceito apresenta as seguintes características fundamentais:

- O que se deve indicar é o conjunto de fatores que promovem efetivamente o êxito, quer dizer, o que é valorizado pelo meio ambiente dos profissionais e dos usuários. As confusões mais freqüentes, às quais é necessário estar bastante atento, são: confundir FCS e norma profissional (interna ou não à organização), por um lado e fatores-chave de sucesso e competência disponível, de outro.

- O número de fatores considerados deve ser limitado; tudo é importante, mas somente alguns elementos são decisivos.

- O nível de competência requerida pode ser avaliado em termos absolutos (mínimo requerido de ordem normativa), mas o que importa é a competência relativa, quer dizer, o diferencial de competências que se estabelece com relação aos concorrentes.

- Os FCS não são invariantes. Sua composição evolui em função dos fenômenos que influenciam as expectativas dos usuários. Estes podem ter uma origem ambiental (fenômenos sobre os quais se pode freqüentemente agir, ao menos indiretamente) ou resultar dos esforços das organizações, em competição entre elas mesmas, que tornam discriminantes fatores considerados anteriormente como secundários. Quando, depois da cotação, o diferencial entre os concorrentes aparece como relativamente fraco, pode-se interrogar sobre a pertinência dos fatoreschaves de sucesso definidos. Com efeito, se todos os concorrentes estão próximos e obtém uma nota satisfatória, deve-se perguntar se o fator-chave de sucesso não pertence ao passado, se seu efeito discriminante pode estar já superado ou se as posições concorrenciais dependem de outros parâmetros. Por outro lado, se todos os concorrentes resultam mal cotados, é necessário se perguntar se não existe um desvio que opera entre a visão do especialista (seu sistema normativo) e a visão do usuário (suas expectativas).

A identificação dos FCS deve ser realizada apoiando-se ao máximo na observação do meio ambiente, analisando o que determina o sucesso de um concorrente considerado particularmente ameaçador, interrogando os interessados, sejam profissionais e usuários. Esta identificação é indissociável 
da identificação dos concorrentes e consiste em explorar, pela reflexão estratégica, certos dados de marketing, interrogando-se sobre a persistência das expectativas observadas e sobre os fatores suscetíveis de modificá-las.

O levantamento de dados sobre FCS se faz por referência ao lugar que se ocupa na rede de cuidados correspondente ao segmento estudado. Ocupar uma certa posição na rede de cuidados específica pode ser, em si, um FCS. Uma vez determinado o espaço a ocupar, convém mobilizar um certo número de recursos e de capacidades de controle para propor serviços percebidos como tendo uma qualidade superior aos de seus concorrentes. A obtenção dos FCS é fruto da pesquisa sistemática sobre tipo, qualidade e volume dos recursos que teriam um efeito discriminante sobre o desempenho relativo dos concorrentes envolvidos.

Para ser operacional, isto é, conduzir à formulação de planos de ação que permitam melhorar a posição concorrencial do estabelecimento sobre um segmento de atividade dado, é necessário que a formulação dos FCS seja precisa. Não se trata de dizer, por exemplo, "são necessários médicos competentes" mas de precisar qual é a competência que faz a diferença; ao invés de "são necessários equipamentos eficientes", identifica-se qual é o equipamento cuja detenção constitui uma real vantagem estratégica.

O que faz o sucesso é aquilo efetivamente percebido pelo consumidor dos serviços ofertados. O fato de que o universo da saúde seja um universo prescritivo complica certamente o problema na medida em que pode haver em certos casos dificuldades para conciliar as expectativas dos profissionais e as dos pacientes. É necessário envolver todas as partes, especialmente os usuários (aqui incluídos os profissionais usuários da rede), na pesquisa dos FCS e evitar assumir a postura dependente de confundir expectativas com normas técnicas de boa qualidade profissional. As ferramentas de informação do marketing, os estudos de imagem, de satisfação e de opinião constituem neste sentido um suporte precioso. É por isto que a dimensão relacional (parcerias, comunicação) é freqüentemente fonte de elementos discriminantes.

É importante salientar que, diferente do valor, os FCS não podem ser idênticos para todos os segmentos de atividade, pois representam a especificidade da atividade. E mais, uma grande semelhança nos FCS de diferentes segmentos deve conduzir a repensar a segmentação.

O objetivo central desta definição é hierarquizar as atividades (os segmentos) em função de sua posição concorrencial.

O método de análise consiste dos seguintes passos:

- $\quad$ identificação dos FCS;

- levantamento dos concorrentes; 
- ponderação dos FCS ou definição do seu impacto ou de seu peso relativo sobre a posição concorrencial o que consiste em distribuir 100 pontos entre os FCS em função de sua importância relativa;

- notação: ato de atribuir nota de 0 a 20 a cada FCS em função do grau de controle real dos mesmos, considerando o controle próprio e também o controle dos concorrentes/parceiros;

- determinação da posição relativa própria e dos concorrentes, através da comparação dos scores pertinentes (o score de cada concorrente é determinado a partir dos produtos do peso e da nota por FCS);

É importante assinalar aqui que a definição da posição competitiva dos concorrentes implica a falta de um conhecimento mais preciso da mesma, uma pesquisa complementar em parte in loco (acumulando-se dados objetivos sobre o controle dos FCS). Assim, evita-se a subjetividade excessiva e erros inerentes a uma mera simulação à distância.

A matriz de análise do controle dos fatores-chave de sucesso com alguns exemplos é a seguinte (Figura 3):

Figura 3 - Matriz de análise dos fatores-chave de sucesso (FCS). Posição competitiva.

\begin{tabular}{|l|l|l|l|l|l|l|l|l|}
\hline Segmento & \multicolumn{5}{|c|}{ Concorrentes - Referência } \\
\hline Fatores-chave de sucesso & Peso & Nota & A & B & C & D & E \\
\hline Competência laboratorial & & & & & & & \\
Cooperação cardiologistas & & & & & & & \\
Acolhimento & & & & & & & \\
Acompanhantes & & & & & & & \\
Disponibilidade scanner & & & & & & & \\
Animação rede generalistas & & & & & & & \\
\hline Score segmento & 0 & 0,00 & 0,00 & 0,00 & 0,00 & 0,00 & 0,00 \\
\hline Posição relativa & & & & & & & \\
\hline
\end{tabular}

Fonte: Crémadez \& Grateau, 1992.

\section{A construção do porta-fólio de atividades. A elaboração de uma visão de conjunto}

O porta-fólio de atividades é uma matriz de valor/posição concorrencial onde são posicionados os segmentos estratégicos de uma especialidade para se ter uma idéia de conjunto e de valor comparativo. Na prática, é um gráfico constituído pelo valor como ordenada e pela posição competitiva como abcissa. Cada segmento é representado por um círculo cujo tamanho representa o volume de 
produção relativo das atividades que ele representa, e sua posição sobre o mapa depende do score obtido quando da avaliação do valor e do grau de controle dos fatores-chave de sucesso o que define sua posição competitiva. O gráfico é dividido em quatro quadrantes, sendo os dois superiores correspondentes a segmentos de alto valor, e os dois inferiores, a segmentos de baixo valor. Os quadrantes à direita referem-se a segmentos de alta posição competitiva, e os da esquerda, a segmentos de baixa competitividade (Figura 4).

Figura 4 - Porta-fólio de atividades.

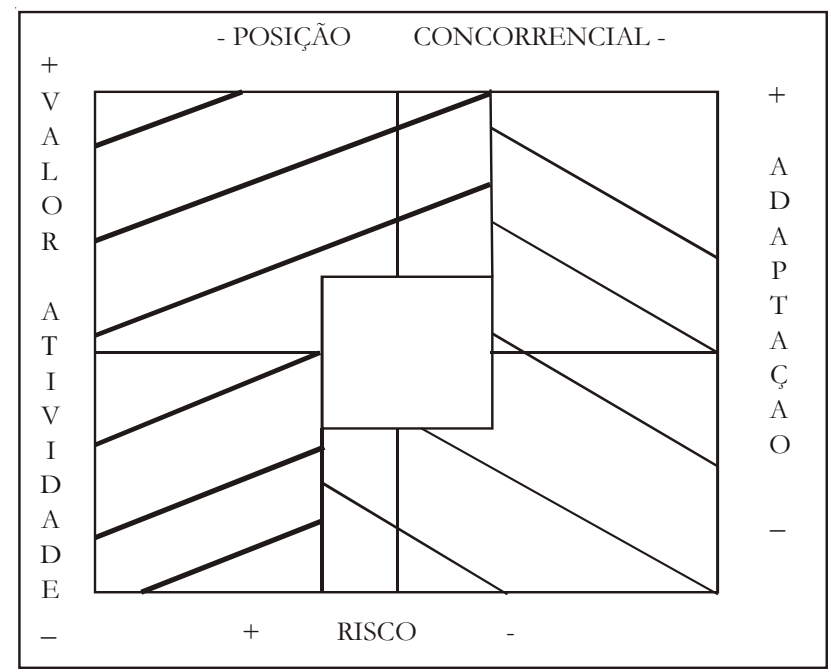

Fonte: Crémadez \& Grateau, 1997.

O exame do porta-fólio deveria permitir um diagnóstico rápido do risco estratégico a que o segmento se expõe, resultante da maior ou menor adaptação da oferta de serviços (valor da atividade) e do esforço requerido para suplantar a concorrência (a posição concorrencial). Também deveria sugerir as grandes linhas de ação de acordo com a posição estratégica no futuro.

O porta-fólio pode estar estruturado em três zonas:

- À direita, uma zona de fraco risco estratégico (tracejado fraco): a inadaptação dos serviços é, na maioria dos casos, compensada pela excelência da posição concorrencial.

- À esquerda, uma zona de forte risco estratégico (tracejado forte): a adaptação dos serviços é, no melhor dos casos, debilitada pela fragilidade da posição concorrencial. 
- No centro, uma zona de indiferenciação (branca), correspondendo às atividades medianamente valorizadas e não discriminadas com relação à concorrência: zona de forte incerteza estratégica.

Os exemplos que constam da Figura 5 foram retirados da obra de Crémadez \& Grateau (1997):

Figura 5 - Exemplos de porta-fólios de atividades.
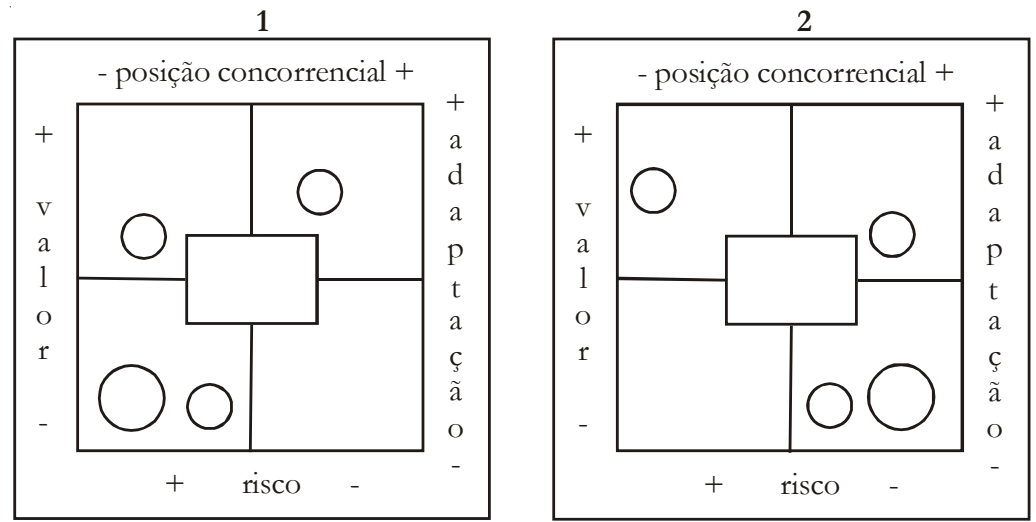

3
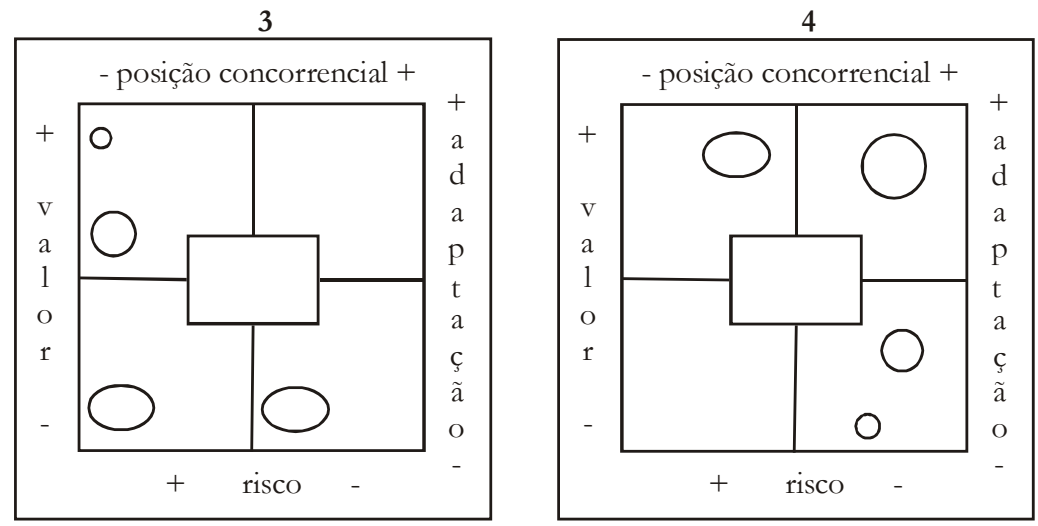

O porta-fólio número 1 representa alto risco, pois somente um segmento de atividade comporta uma boa posição concorrencial. Em contrapartida, está medianamente adaptado, pois cerca da metade do volume de atividade se destina aos segmentos mais bem posicionados em termos de valor. O principal problema da instituição será desvencilhar-se dos segmentos inadaptados a fim de canalizar seus recursos em direção aos segmentos mais bem adaptados, e notadamente em direção ao segmento que deveria ganhar em posição concorrencial. 
Nesta ocasião, será necessário analisar detalhadamente o conteúdo, em termos de população, patologia, tecnologia e de modo de atendimento do segmento mais importante (em volume de atividades) e não tão bem posicionado. Esta investigação permite "separar o joio do trigo" e revalorizar as atividades referidas favorecendo aquelas que, graças a uma orientação particular, fornecerão uma resposta mais adaptada as necessidades dos usuários. Trata-se, em certos casos, de se concentrar sobre a resposta específica a uma categoria de usuários que aparece como majoritária em um segmento considerado. Em outros casos, será conveniente adotar um modo de atenção mais bem adaptado e mudar de posição na rede de cuidados. Poderá ser o caso, ainda, de reduzir o número de patologias atendidas ou de concentrar-se sobre aquelas que correspondem mais à vocação do estabelecimento. Enfim, o encaminhamento poderia ser o de modificar as tecnologias utilizadas a fim de abrir um novo campo de ação. Assim, o desengajamento de um segmento de atividade não é sinônimo de abandono puro e simples; ele deve ser acompanhado de um plano de ação específico e, eventualmente, de um esforço de investimento.

O porta-fólio número 2 demonstra pouco risco: somente um segmento se coloca em posição concorrencial desfavorável. É, em contrapartida, pouco adaptado, já que o segmento que tem a pior posição concorrencial é precisamente aquele que representa o melhor valor. Entretanto, é difícil fazer evoluir este porta-fólio de forma constante, via redistribuição dos recursos entre os segmentos que o compõem. Com efeito, quando uma importante parte da atividade tem fraco valor, mas uma posição concorrencial mais forte, é difícil desembaraçar-se dela. Esta situação pode, em certos casos, traduzir uma insuficiência de difusão das tecnologias e/ou do savoir-faire. Uma das saídas pode ser então realizar a transferência dos segmentos mal posicionados, liberando assim recursos que poderão ser reorientados em direção ao segmento de atividade mais valorizado, mas onde se pode melhorar a posição concorrencial. Em certas situações extremas, onde há o risco de ser definitivamente ultrapassado em relação a este último segmento, por falta de uma reação mais rápida, será necessário investir sem esperar os efeitos da transferência. Neste caso, é necessário ser extremamente vigilante a fim de que a transferência se faça o mais rápido possível e que os recursos liberados possam ser reorientados em direção a outros domínios. Caso contrário, a longo prazo, poderá haver uma captação de recursos indevida, que prejudica as atividades que poderiam se beneficiar desses recursos.

O porta-fólio número 3 é um porta-fólio ao mesmo tempo mais arriscado e menos adaptado, que denota um fraco domínio do setor considerado. Necessita, antes de tudo, de uma análise precisa da concorrência, já que o encontramos freqüentemente nos domínios de atividade que estão submetidas a uma evolução científica e/ou técnica que abre novas perspectivas. Neste caso, será 
necessário antes de tudo voltar a atenção sobre os dois segmentos mais valorizados, a fim de definir as estratégias que permitirão fazer progredir sua posição estratégica. É necessário por vezes se desembaraçar o mais rapidamente possível dos segmentos de fraco valor. Entretanto, o tempo do processo de desengajamento dependerá de uma aceitação psicológica por parte dos profissionais ligada à evolução dos segmentos de alto valor.

O porta-fólio número 4 aparece como mais promissor e equilibrado, pois os segmentos menos importantes (em volume de atividade) não estão bem posicionados em termos de valor. Denota um forte controle do domínio considerado. As preocupações são, neste caso, de duas ordens: de um lado, controlar as manobras da concorrência para evitar surpresas desagradáveis e evitar a super alocação de recursos decorrente da influencia interna que poderão adquirir os responsáveis pelo domínio em questão.

Estes quatro exemplos mostram que, nos casos extremos, é necessário, antes de tudo, preocupar-se com os concorrentes e com o meio ambiente, descobrir as oportunidades e ameaças e, que convém, antes de tudo, em certos casos, analisar com detalhe o conteúdo das atividades, a partir dos pontos fortes e fracos identificados.

Da leitura dos porta-fólios, podemos depreender que os segmentos prioritários são os de alto valor. Em geral, deveriam ser estimulados os segmentos de alto valor. Porém, nem sempre um segmento de baixo valor é sinônimo de abandono do mesmo (especialmente quando o volume de atividade é grande e a atividade não é realizada por outros). Por outro lado, quando os segmentos apresentam uma baixa capacidade competitiva, mas alto valor, significa que a melhor estratégia seria a de investir na melhoria da posição competitiva, aumentando o rendimento e o controle dos fatores-chave de sucesso. O ideal é encontrar os segmentos à direita do porta-fólio. Porém, o porta-fólio não deve inspirar movimentos de forma mecânica: ele é um documento para ajudar a pensar uma estratégia.

O porta-fólio serve para determinar prioridades, para fixar a estratégia do hospital em termos de três possibilidades de objetivos, principalmente:

- Desenvolver um segmento: identificar as atividades que deve ser expandidas, priorizadas, desenvolvidas particularmente. Este objetivo em geral se confunde com a estratégia de diferenciação ou de agregação de um plus de valor percebido como melhora de qualidade, podendo implicar mais custos, em investimentos específicos para enfrentar os pontos fracos típicos dos FCS. O desafio aqui seria buscar a estratégia de diferenciação que envolvesse relativamente menos custos.

- Manter ou estabilizar um segmento: definir os segmentos a manter em "banho-maria", no mesmo nível de desenvolvimento histórico, se possível re- 
duzindo custos. Aqui podem constar segmentos de alta competitividade e valor, os quais poderiam ser apenas mantidos na atual posição, reduzindo custos e liberando recursos para outras atividades.

- Reduzir o recrutamento da clientela para um segmento: definir os quais seria necessário recortar ou focalizar, desestimular, diminuir, negociando a transferência parcial ou total de atividades para a rede (entende-se por focalização privilegiar um determinado tipo de usuário ou nosologia).

Para Porter (1982), haveria três estratégias genéricas, mais bem discutidas adiante a partir da obra de Crémadez \& Grateau, 1997: diferenciação, que implicaria definir uma oferta única, exclusiva, diferenciada, percebida por todos como superior qualitativamente, cujo acesso também poderia ser diferenciado; liderança no custo, que representaria diminuir custos para liberar recursos para outros segmentos, sem comprometer a qualidade; focalização (que pode evoluir como estratégia de custos e/ ou diferenciação).

\section{Elaboração dos planos de ação}

Os planos incluem os esforços a realizar para agir sobre a rede de médicos de consultório (que referem pacientes), para implementar associações, para formar médicos e pessoal paramédico, para comunicar o savoir-faire controlado, para adquirir novas tecnologias, para implementar novos modos de atenção etc.

O Plano de Ação é o 'que fazer' para implementar a Estratégia. Consistiria em um conjunto de atividades, tais como:

- Formas de apropriação/desenvolvimento dos FCS visando a enfrentar os pontos fracos identificados na análise incorporação de tecnologias e de recursos humanos, treinamentos, desenvolvimento de fatores de qualidade etc.

- Ações de negociação e de comunicação internas ao hospital e com a rede, incluindo o estabelecimento de sinergias e parcerias externas.

- Ações visando a revalorizar um segmento, atuar sobre algum critério da análise do valor de baixo score, passível de intervenção (quando a decisão política é de buscar aumentar o valor).

- Ações visando a modificar o modelo assistencial, as formas de atendimento que caracterizam um determinado segmento e o perfil de tecnologias utilizadas.

- Ações de natureza social e intersetorial.

- Ações que desenvolvam objetivos tipicamente médicos, como determinadas pesquisas. 
A consolidação de um plano de ação é um contínuo retomar da análise estratégica do valor e da posição competitiva, com o objetivo de aumentar o controle dos FCS, para melhorar a posição estratégica geral. O plano culmina com a definição dos indicadores de monitoramento das ações para que seja possível acompanhar as mudanças propostas.

\section{Avaliação das dificuldades encontradas}

Esta avaliação apóia-se, principalmente, em dados colhidos na Unidade de Análise Estratégica do Centro Hospitalar de Lille, nos encontros mantidos durante nossa visita àquele complexo hospitalar, em encontros que aconteceram no Brasil, quando da vinda de Monsieur Le Ludec, ${ }^{2}$ em documentos citados que fazem parte do material instrutivo do enfoque e, em parte, em uma análise ainda parcial de algumas experiências brasileiras.

Entre as dificuldades gerais, destacam-se: o ceticismo, a descrença na mudança, as barreiras de linguagem, a desconfiança, a indiferença e a recusa a comprometer-se.

Em relação ao diagnóstico, as maiores dificuldades residem na ausência de sistemas de informação ao início da démarche, na opacidade da atividade da concorrência, na seleção da informação qualitativa, na debilidade da base documental e na pobreza dos dados epidemiológicos e/ou na dificuldade de sistematizá-los.

$\mathrm{Na}$ fase da segmentação, alguns problemas se tornam evidentes:

- a segmentação é um conceito difícil de se apreender: o grupo médico tende a confundir segmento e grupo homogêneo de doença, em circunstâncias que a segmentação das práticas de trabalho pode obedecer a outros critérios (como o tecnológico, o gerencial e o populacional), para além do critério entidade epidemiológica. Isto gera algumas reticências por parte dos profissionais;

- a linguagem utilizada não pertence ao vocabulário médico;

- há uma tendência para definir uma segmentação "territorial", reflexo de uma luta pelo poder ou reveladora de problemas latentes.

Sobre a fase da análise estratégica, detectaram-se outros problemas:

- a lógica das grades não é facilmente percebida, há uma interrogação múltipla sobre a utilidade da ponderação e da notação;

Monsieur Le Ludec é um dos responsáveis pelo desenvolvimento da demarche stratégique em Lille, tendo acompanhado a experiência por nove anos. 
- a notação é considerada definitiva quando se examinam todos os segmentos;

- os comentários devem ser objeto de um consenso absoluto, o que torna a formalização cansativa;

- os serviços em posição de monopólio se prestam menos a este tipo de análise;

- surge a necessidade da busca de informações adicionais e, muitas vezes, existe dificuldade na obtenção dos dados.

O processo de elaboração dos planos, finalmente, enfrenta algumas dificuldades:

- os objetivos são às vezes pouco ou mal definidos por falta de comprometimento;

- $\quad$ ausência de participação de profissionais não médicos do hospital;

- planos de ação de natureza essencialmente médica, sem ligação com um projeto social;

- indicadores às vezes difíceis de pôr em prática.

\section{Análise crítica geral}

Em primeiro lugar, um dos maiores méritos da démarche é ensejar a definição de objetivos médicos e desenvolvimento de um processo de a avaliação das atividades institucionais e da missão organizacional. O grande objetivo da busca da articulação gerencial de um projeto médico é, em grande medida, cumprido. Durante a nossa visita à Unidade de Análise Estratégica do CHRU, pudemos levantar e revisar os Projetos de Estabelecimento concluídos ao longo de quatro anos de aplicação exaustiva da démarche. Praticamente todos os serviços dos vários hospitais desta verdadeira holding hospitalar foram envolvidos nesta lógica gerencial. Os estágios de desenvolvimento do projeto da démarche variam de serviço a serviço. Porém, esta nova racionalidade gerencial já é uma realidade, reconhecida na França como um dos modelos de gestão respeitados.

A aplicação da démarche não é um processo apenas formal, que se resume à documentação pertinente aos projetos de estabelecimento centralizados na Unidade de Análise Estratégica. Sua lógica de implementação, baseada em reuniões colegiadas, insere-se no objetivo de motivar uma comunicação ampla a serviço de uma mudança cultural. O desafio implícito é articular um coletivo em torno de um projeto único, que considere a rede. Os resultados da démarche medem-se ao longo do tempo, em um processo interativo, sempre exploratório, capaz de impactos culturais decisivos. Isto não é uma tarefa simples, assimilável à condição de uma gestão racionalizadora ou estabilizadora, de efeitos imediatos. Trata-se 
de construir a colaboração, através, principalmente, de novas parcerias, do aprofundamento de sinergias internas e de uma nova postura, mais comunicativa entre os diferentes profissionais/atores.

A Coordenação da Unidade de Análise Estratégica garante, no entanto, a existência de resultados palpáveis, que constam de trabalhos em vias de publicação, a que tivemos acesso durante a visita. Estes trabalhos, como o de Thomas Le-Ludec (1995), acentuam em geral a montagem de estruturas transversais de colaboração entre hospitais, especialidades e segmentos. A produção de resultados instrumentais, situados na lógica da otimização da alocação de recursos e da colaboração com a rede, é, sem dúvida, uma necessidade prática, premente, de caráter legitimador.

Problematizemos um pouco mais o enfoque. Uma das principais restrições à démarche, surgida nas nossas discussões, refere-se à eventualidade da segmentação estratégica reforçar a atomização, ao invés de ajudar a integração (por ser muito molecular). Esta crítica é bastante séria e merece uma discussão. Existe a possibilidade de que a segmentação se paute pela especialização do conhecimento médico e pela disputa de territórios. Por outro lado, deve considerar-se que a aplicação geral do enfoque é feita serviço por serviço, disciplina por disciplina. Que a análise estratégica dos segmentos é um trabalho feito no nível de pequenos grupos. Surgem perguntas naturais do tipo: como promover a agregação, a coordenação horizontal, a fim de garantir um projeto integrado, prioridades únicas por estabelecimento? Como compensar a tendência à diferenciação implícita em uma segmentação muito molecular?

$\mathrm{Na}$ realidade, este problema se coloca para fora da especialidade, pois considerando a especialidade em si, uma segmentação bem feita forneceria as bases técnicas necessárias para uma análise de prioridades que permitiria chegar pela via da discussão crítica e democrática a um consenso de especialidade. Um bom detalhamento dos grupos homogêneos de atividades ajudaria a estabelecer uma dinâmica de avaliação voltada para a caracterização da posição estratégica diferencial dos mesmos grupos. Não se é bom em tudo. Há áreas de excelência e de não excelência. A não diferenciação de atividades poderia ocultar particularidades e defasagens em posição estratégica dificultando o processo de priorização de atividades. Por outro lado, uma segmentação baseada em um diagnóstico médico rico e na tentativa de agrupar atividades homogêneas a partir da conjugação de vários critérios técnicos e sociais, pode ajudar a desmontar feudos montados a partir do exercício do poder e da informalidade.

A questão se refere ao aspecto interespecialidades. Com base nas conversações que mantivemos na UAS, podemos assinalar que a necessidade e a possibilidade da integração dependem de uma dinâmica que obriga a agregar e desagregar iterativamente os grupos de trabalho e a procurar instâncias de discussão mais abrangentes, que superem o microcosmo do segmento, da disciplina e até 
do hospital. Um dos grandes desafios do método está relacionado à existência de fóruns ampliados de agregação de interesses, onde se processe o grande acordo ou a grande negociação do projeto hospitalar, imanente à lógica da démarche.

É importante frisar que se, de um lado, a segmentação pode ser considerada um fator de diferenciação, não é menos verdadeiro, por outro lado, que é a partir da categoria celular de segmento que a démarche procura 'costurar' a idéia de uma rede integrada de oferta de cuidados. Uma das preocupações mais marcantes do plano de ação consiste deliberadamente em destacar as sinergias e parcerias potenciais inerentes a cada segmento, para a partir daí explorar possibilidades de estruturas em rede. Não se deve esquecer que um dos objetivos nucleares do enfoque é justamente o de criar um movimento de transformação do hospital em uma organização aberta. Detectar os pontos de sinergia e de complementaridade é a base para a formulação de lugares organizativos de discussão mais ampliada. Finalmente, devemos reforçar a idéia de que a segmentação pode obedecer a critérios mais integradores como tipo de atendimento ou população, para além de uma divisão baseada na diversidade de patologias ou tecnologias. Desta maneira, procuramos sustentar o argumento de que a segmentação estratégica é a base de um processo contraditório de diferenciação e de integração, em que a busca da complementaridade e da colaboração é um dos requisitos essenciais, a ser garantido por um tipo de metodologia política de negociação que implique o desenvolvimento de discussões transversais e da montagem de estruturas em rede.

Uma das maiores dificuldades está relacionada à difícil aplicação da démarche em situações de monopólio. Parece-nos que a démarche francesa supõe um contexto de menor restrição de recursos e de competição, o que nem sempre acontece nos países em vias de desenvolvimento. Pode-se argumentar que em alguns espaços desses países vigoram essas condições de contexto, mas não em todos. Esta situação não invalida o enfoque, apenas o restringe em sua aplicação. Mesmo em uma situação de concorrência precária ou inexistente, a simulação da concorrência que pode virtualmente passar a existir ajuda a estabelecer estratégias para aprimorar o domínio dos fatores-chave de sucesso das atividades.

De qualquer maneira, a perspectiva de aplicação do enfoque dependeria de simplificações e adaptações ao nosso contexto. Vamos referir-nos, em geral, às principais reformulações necessárias, de acordo com as discussões preliminares desenvolvidas no nosso âmbito.

Tudo indica que uma adaptação dos critérios envolvidos na determinação da capacidade de atração se faz necessária. Na realidade, a relação de critérios e o seu peso específico são variáveis, ajustáveis no método, em função das características do mercado de serviços de saúde em pauta, em cada momento. Nesta medida, a idéia de se trabalhar com um elenco menor de variáveis representati- 
vas, cuidadosamente escolhidas, é algo absolutamente normal, tendo em vista o contexto local e as possibilidades de manuseio da metodologia.

Outro aspecto que pode ser objeto de adaptações refere-se à definição de objetivos. O método original não enfatiza a criação, pelo menos explicitamente, de novos segmentos como parte das principais estratégias, embora esta possibilidade esteja incluída na abordagem francesa. Dada a necessidade eventual de se abrirem novos serviços, em função de carências sanitárias, situação comum em países com poucos recursos, a estratégia deveria acrescentar, às três dimensões de objetivo do enfoque (desenvolver, estabilizar, reduzir), a meta da criação de novas atividades.

Nesta linha de raciocínio, consideramos necessário reforçar os critérios populacionais e epidemiológicos, para contrabalançar as características da démarche relacionadas a um modelo típico de planejamento baseado na oferta. Esses critérios ligados à detecção de necessidades de saúde deveriam ser levados em conta de maneira mais explícita na análise da possibilidade de abertura de novos grupos de atividades e na análise do valor dos grupos de atividades (re)organizados valendo-se da estrutura da oferta preexistente. Devemos acrescentar, porém, para fazer justiça ao método, que o dado epidemiológico está embutido no critério possibilidades de crescimento ou desenvolvimento dos segmentos como parte da análise do valor estratégico dos mesmos ou de seu nível de prioridade relativo.

Com estas considerações gerais, concluímos aqui nossa apresentação panorâmica do método de planejamento da démarche, não sem antes afirmar que vemos este enfoque como um modelo de gestão estratégica e comunicativa da realidade hospitalar com enormes possibilidades práticas, como pudemos constatar na nossa experiência de aplicação no Brasil, que não é desprezível.

\section{A Conquista de Vantagens Concorrenciais: estratégias genéricas}

Dispõe-se de uma vantagem determinante sobre seus concorrentes quando se detém a primazia de uma competência fundamental para se ter êxito em um segmento de atividade. A vantagem concorrencial se fundamenta no fato que os usuários (pacientes, quem referencia...) reconhecem à oferta de um concorrente um acréscimo de valor suficiente para que prefiram a ele recorrer. Este diferencial de valor se resume em geral a uma relação qualidade/preço. Em circunstâncias em que a realidade de preços não impera, pode-se apreciar o valor concedido a um serviço pelos esforços feitos para pela clientela para ter acesso a ele (deslocamento, espera consentida...). 
Podem-se seguir duas vias estratégicas gerais para aumentar a base de vantagens concorrenciais disponível: aumentar o valor para o usuário ou envolver menos recursos sem diminuir o valor do serviço, tal como percebido pelo usuário em termos de qualidade.

A estratégia de diferenciação acentua o valor. Esta via supõe a possibilidade de criarmos um acréscimo de valor superior ao custo suplementar envolvido para esse fim. A via dos ganhos em eficiência, em troca, supõe que sejamos capazes de racionalizar a produção de tal maneira a não afetar a qualidade e a que esta racionalização gere um ganho de recursos suficiente para que sua realocação produza uma vantagem estratégica dominante.

Para detectar as fontes de vantagens concorrenciais, seria necessária uma visão analítica dos processos de criação de valor no interior de uma empresa e de suas interações, isto é, analisar sua cadeia de valor e a estrutura de custos correspondente. $\mathrm{O}$ termo cadeia de valor (oriundo de M. Porter) corresponde à descrição das atividades que a organização implementa para realizar e colocar à disposição dos clientes seus produtos ou serviços.

Haveria vários tipos de atividades:

- A gerência e o conjunto de atividades estruturantes, incluindo a negociação com os financiadores e os fornecedores, a organização de atividades, a gestão de recursos humanos, o financiamento do investimento, os estudos de mercado, as escolhas tecnológicas e de tipo de serviços etc.

- As atividades de suporte operacional: considera-se atividade de suporte operacional toda atividade logística que não corresponde a um fator chave de sucesso para determinado segmento da atividade, mas que é necessária para a realização da prestação de serviço. Em geral, esta atividade corresponde à logística não médica, passível de ser terceirizada porque não corresponde a um savoir-faire determinante no jogo concorrencial .

- As atividades operacionais principais: todas aquelas que concorrem principal e diretamente para a realização do serviço. Podem ser mais ou menos específicas de um segmento ou ser compartilhadas entre vários, como é o caso da estrutura tecnológica relativa aos setores de imagem e de biologia, por exemplo. Estas tecnologias se organizam em torno de processos de atendimento mais ou menos formalizados, precisos e controlados. A concepção e a condução destes processos deveriam estar no centro da reflexão sobre ganhos em eficiência e em valor. Esta dimensão depende totalmente da experiência dos profissionais (médicos e para médicos) e não costuma ser objeto de intercâmbio de experiências. É nesses processos de atendimento que as práticas rotineiras dominam e são raramente questionadas de maneira regular e organizada. Porém, são causas habituais de acréscimos no custo: redundância de exames, exames inúteis e custosos, entre outros. 
Os diferentes componentes de uma cadeia de valor não são independentes. Há conexões entre os vários componentes da cadeia de valor de um mesmo segmento e entre componentes de segmentos diversos. Estes componentes também apresentam interfaces com componentes da cadeia de valor de outras instituições com as quais a organização mantém relações de referência de pacientes, de fornecimento e compra de produtos ou de intercâmbio científico.

As vantagens concorrenciais seriam obtidas através da intervenção nestas interfaces como trabalhando no nível de cada componente gerador de valor. A exploração das interfaces é uma fonte importante de vantagens, que subentende a existência de um bom sistema de comunicação/acompanhamento. Crémadez inclui a logística médica e a comunicação informatizada como atividades operacionais principais justamente por este motivo.

Há inúmeros exemplos de exploração das interfaces: a saída de um serviço clínico e a entrada em outro; a relação emergência-serviços para o encaminhamento dos pacientes e a coerência de seu tratamento; a interface medicina-cirurgia em algumas patologias e atos, como a cancerologia, as hérnias de disco, a insuficiência coronariana, os transplantes etc. e as relações de referência e contra-referência de pacientes com a rede.

O conhecimento da estrutura de custos dos segmentos é de fundamental importância para a definição de estratégias de obtenção de vantagens. A estrutura de custos de uma atividade caracteriza-se, de maneira sintética, pela proporção de custos fixos de origem central, de custos fixos específicos e de custos variáveis. Os custos fixos mais importantes das atividades hospitalares correspondem à infra-estrutura de internação/alojamento, ao pessoal e às tecnologias implementadas.

Quando a estrutura de custos de uma atividade revela uma preponderância dos custos fixos alocados sobre os custos fixos específicos e os custos variáveis, seria interessante optar pela busca de vantagens estratégicas pelos custos. Quando se revela uma preponderância do custo variável unitário direto e de custos fixos específicos em relação aos custos fixos centrais alocados, seria necessário pensar em termos de diferenciação. A diversidade de atividades de um estabelecimento leva a adotar um mix de estratégias genéricas.

Em outras palavras e segundo nossa interpretação, a estratégia de custos, em geral, seria justificada principalmente, quando os segmentos dependem de tecnologias e de infraestrutura de internação custosas e compartilhadas (que não representam custos fixos específicos). Isto porque seria necessário considerar estes recursos e minimizar a disputa de maneira a garantir recursos para todos, o que demandaria uma racionalização, como, por exemplo, controlar o tempo de permanência, baixando custos. A não ser que o segmento apresente forte potencial de diferenciação, o fato de não contar com recursos próprios (ou 
potencial de captação destes recursos) que gerem custos fixos, como tecnologias, sugere que a estratégia de diferenciação não seria a melhor opção. Neste caso, o investimento necessário em capacidade instalada, tecnologias e recursos humanos especializados representaria relativamente uma nota menor, devido ao baixo controle, diminuindo o score resultante da análise de valor do segmento. $\mathrm{O}$ investimento ainda por ser realizado dificultaria a obtenção de vantagens comparativas via diferenciação.

\section{A estratégia fundada nos custos}

É indispensável conceber uma estratégia de custos em todos os segmentos de atividade que precisam de infra-estruturas caras e compartilhadas, que apresentam um custo variável unitário pouco elevado e reduzidas formas de se diferenciarem expressivamente dos concorrentes.

Genericamente, a estratégia de custos consiste em privilegiar atividades que reforcem o potencial de sinergia já existente - atividades para as quais o controle dos custos compartilhados é um savoir-faire determinante -, bem como em eliminar custos específicos não justificados para garantir a conexão mais eficaz entre cadeias de valor.

O controle do custo operacional dos recursos humanos supõe investimentos em formação e em organização. Para o pessoal paramédico, recomenda-se uma formação polivalente e/ou a criação de grupos polivalentes que permita uma maior flexibilidade na sua distribuição pela organização, garantindo um forte grau de aderência a cada serviço específico para onde foram destinados (uma posição intermediária entre a gestão global ou centralizada do corpo de profissionais e uma destinação rígida no interior de um). Para o pessoal médico, recomenda-se uma formação que fomente uma visão multidisciplinar, assim como o estabelecimento permanente de contatos visando à formulação de consensos sobre as práticas profissionais.

Os custos de infra-estrutura são sensíveis à taxa de ocupação e de rotatividade, por um lado, e à adequação dos pacientes à vocação da estrutura, por outro.

Em uma estratégia de custos, seria necessário maximizar a taxa de ocupação, o que dependeria, em boa medida, de estruturas menos rígidas, mais flexíveis, que se adaptem às evoluções do mercado, ao rendimento e à própria evolução da missão da organização.

A rotatividade está ligada ao tempo de permanência dos pacientes. Para reduzir custos, seria necessário combater alguns procedimentos relacionados à entrada e à saída de pacientes e privilegiar estruturas de atendimento especializa- 
do, programado e de duração determinada, que explorem as sinergias entre atividades.

É conveniente, ainda, regular as relações entre as estruturas técnicas de apoio diagnóstico e terapêutico e os serviços clínicos, levar em conta os pontos de estrangulamento não superáveis a curto prazo e recorrer eventualmente aos meios de parceiros externos.

A adequação depende do grau de correspondência entre o tipo de clientela e a especialização da estrutura. A inadequação é fonte de desperdício de recursos e resulta, em boa medida, de serviços de triagem e de orientação que funcionam mal.

O controle do fluxo de pacientes é um elemento fundamental da redução de custos. Uma boa comunicação com os serviços que referenciam pacientes e com aqueles que complementam um cuidado é fator chave dessa estratégia.

\section{Os custos tecnológicos}

O controle destes custos depende da oportunidade de aquisição de equipamentos a preços estáveis, conhecidos e que favoreçam um prazo de recuperação curto dos investimentos. Devem-se avaliar os riscos no caso de superposição de equipamentos nos diferentes concorrentes e evitar equipamentos ociosos ou semi-ociosos.

Em segundo lugar, é necessário considerar a concentração de equipamentos como fator de economias de escala e seu compartilhamento quando isto é necessário para atingir a massa crítica de atividade correspondente ao limiar de rentabilidade.

O controle da aprendizagem da apropriação das tecnologias é fundamental. Todas as fases envolvidas na implementação de uma tecnologia, para além da mera manipulação, devem ser objeto de um treinamento que envolva um conjunto diversificado de pessoas, de modo a não ficar restrito ao operador. Este processo deve envolver também o controle e a gestão do processo de substituição tecnologias.

Os ritmos de utilização dos equipamentos, a fim de evitar os custos adicionais decorrentes de flutuações (super ou subutilização), é outro importante fator no controle de custos tecnológicos, que depende de um bom controle da demanda e dos fluxos de chegada.

Um elemento fundamental numa estratégia fundada nos custos é a pesquisa de inovações tecnológicas capazes de diminuir o tamanho da infra-estrutura necessária e/ou de gerar uma substituição tecnológica que permita uma maior 
programação do atendimento, um controle crescente dos prazos de tratamento e uma tendência para formas de tratamento que impliquem tempos de internação mais reduzidos (tecnologias para cirurgias menos invasivas, por exemplo).

\section{Os custos variáveis}

Representam uma fração menor do conjunto de recursos alocados em um estabelecimento hospitalar, mas a margem de liberdade depende em grande parte de seu controle.

A redução de custos variáveis depende de duas alavancas fundamentais:

- A gestão do abastecimento e de estoques que repousa no desenvolvimento de competências específicas.

A capacidade de negociação representa um fator importante de redução dos custos de abastecimento que não é implementado devidamente. Baseia-se na seleção, conhecimento do mercado, prática da concorrência , utilização dos efeitos de tamanho e de escala nas compras. Já a competência em explorar a sensibilidade da estrutura de custos dos fornecedores ao comportamento do cliente: estabilidade das especificações, prazos de pagamento, regularidade e volume dos pedidos unitários, etc. são fatores de redução dos custos dos fornecedores dos quais podemos tirar partido nas negociações. A terceira competência específica é o rigor na definição das especificações dos produtos comprados e, principalmente, na definição de seu acondicionamento unitário em função das práticas de consumo (evitando o desperdício devido a acondicionamentos não adaptados, por exemplo).

- A formalização das práticas de atendimento e sua análise crítica regular

A implementação de rotinas profissionais pela formalização é indispensável para controlar os custos variáveis, pois a formalização atuaria positivamente, em termos de eficiência, sobre os três componentes fundamentais dos custos variáveis: o consumo de atos, de produtos farmacêuticos e de material de consumo.

\section{Estratégias de diferenciação}

A diferenciação, em geral, confunde-se com o desenvolvimento de uma competência médica específica, associada, em certos casos, ao controle de certas tecnologias. Esta é a via de diferenciação mais comum historicamente. Mas não é e não deveria ser a única.

A diferenciação pode operar modificando um ou vários elementos da cadeia de valor, explorando as relações entre os elementos das cadeias de valor de 
dois segmentos que apresentam sinergias potenciais e modificando a conexão e a coordenação com os parceiros externos. Todos estes elementos podem desempenhar um papel determinante na satisfação global do cliente.

\section{Modificação da cadeia de valor de um segmento}

Esta estratégia pode consistir em introduzir um serviço complementar na cadeia de valor de um segmento: desenvolvimento de cuidados paliativos no tratamento do câncer; aumento do número de formas de preparação do parto em obstetrícia. Pode significar, também, completar ou modificar apenas um componente da cadeia de valor: a passagem de um "serviço-porta de entrada" (triagem) para a admissão direta pode ser uma via de diferenciação que questiona os elementos acesso, acolhimento, comunicação clientes-sistema de referência da cadeia de valor de vários serviços. É o complemento normal da especialização dos serviços clínicos. Com efeito, a especialização tem pouco impacto, se não acompanhada de uma ampliação das relações com o sistema de referência que permita o recurso direto.

Pode-se compensar a perda de flexibilidade induzida pela especialização pela criação de estruturas intermediárias concebidas para responder às necessidades dos pacientes fora da etapa aguda e para economizar recursos raros e custosos (o compartilhamento destas estruturas entre serviços é extremamente necessário e ainda pouco experimentado). Uma maior colaboração com os parceiros externos pode evitar alongamentos indevidos das internações.

\section{Modificação da conexão e coordenação entre dois segmentos que apresentam sinergias}

Corresponde a remodelar as relações entre dois segmentos com a finalidade de explorar novas sinergias: estreitar os laços entre os médicos especializados e a cirurgia em torno da problemática dos transplantes ou entre a pediatria e a obstetrícia para oferecer um serviço mais completo para as futuras mães, gerando efeitos positivos no sentido do recurso posterior a este hospital no que concerne ao acompanhamento dos filhos.

\section{Modificação da conexão e da coordenação com parceiros externos}

Significa o estabelecimento de parcerias visando a suprir carências de equipamentos, desenvolver pesquisa clínica, participar do ensino universitário ou de 
pós-graduação, diminuir o tempo de permanência e a beneficiar-se da transferência de tecnologia etc.

Como a diferenciação pode implicar em mais custos o grande desafio que enfrenta esta estratégia é a escolha de formas de diferenciação relativamente menos custosas, em que o ganho em valor ou qualidade do serviço prestado supere os acréscimos em custo.

A estas duas estratégias genéricas deveríamos acrescentar uma terceira, já indicada anteriormente, a Focalização, que consistiria em recortar um segmento ou em privilegiar dentro do mesmo uma determinada categoria de usuário, de nosologia clínica ou de tipo de tecnologia de atendimento. Por exemplo, restringir o ambulatório de adultos de um determinado hospital psiquiátrico à população adscrita a uma área programática menor ou às patologias de maior complexidade. Ou ainda, privilegiar dentro do mesmo um tipo de atendimento aquele mais programável, referenciado (paciente ligado a uma determinada equipe), de natureza multidisciplinar.

\section{O Hospital como Estrutura em Rede}

Como já foi bastante salientado, um dos objetivos estratégicos do enfoque em pauta é o estabelecimento de redes de cooperação interna e externa, e um tipo de estrutura organizacional coerente com essa perspectiva.

Crémadez e Grateau (1992) reconhecem a possibilidade de quatro tipos de cooperação eventual. Neste sentido recriam, para o contexto sanitário, as formas de aliança estratégica definidas no texto sobre Política Geral de Empresa: Stratégie, Structure, Décision, Identité, do grupo Strategor (1997). Estes tipos são:

- Parceria vertical: corresponde a coordenar os papéis dos estabelecimentos no seio de um mesmo processo de prestação de cuidados. Por exemplo, integração entre os níveis primário, secundário e terciário de um determinado domínio de atividade (implantação de um sistema de referência e contra-referência materno-infantil).

- Integração Conjunta: corresponde ao compartilhamento de uma tecnologia, especialmente de recursos raros (diagnóstico e terapia). Aqui, sem se acabar completamente com a concorrência virtualmente existente, congela-se um elemento.

- Adicionamento ou acréscimo: neste caso, não há mais concorrência. Articulam-se estabelecimentos ou unidades em torno de serviços completos. Há a constituição de um potencial comum. Por exemplo: organi- 
zação de pesquisa multicêntrica. Neste caso, a concorrência virtual cede o lugar à competição interna.

- Complementaridade: consiste na valorização das contribuições complementares, na geração de uma prática diferenciada útil para todos os cooperantes. Exemplo: cooperação entre redes de cuidados, entre a medicina e a geriatria, substituindo a concorrência pela cooperação.

É importante resgatar a idéia de que o processo de integração estratégica do enfoque em questão não se coaduna com uma visão monolítica da saúde pública, representada pela proposta de um único modelo de integração incutido pela regulação central, considerado um modelo de otimização. A rede deve ser vista como o resultado da imbricação das oportunidades de diferentes formas de cooperação de que se oferecem aos atores que compõem um sistema. É um conceito que repousa sobre a capacidade de negociação e contratualização dos atores, já referida. O papel da regulação seria o de incitar, ativar e coordenar este processo de aproximação e de relacionamento, respeitando a diversidade. Neste particular, a via da responsabilização dos atores nada tem a ver com um tipo pesado de planificação tecnocrática (Rivera, 1998).

A respeito do postulado da organização em rede interna, é necessário assinalar que, em nossos dias, o paradigma predominante deveria ser o da flexibilidade e adaptabilidade organizacional. Postulam-se estruturas planas, com um número mínimo de níveis hierárquicos e unidades de pequeno tamanho e grande latitude de ação. Este ideal organizacional já é uma realidade no ambiente hospitalar. O grande problema hospitalar é, porém, a falta de integração ou a diferenciação exagerada, que deve ser compensada.

A estrutura em rede interna, vista como alternativa à diferenciação desmedida, é definida como a organização das relações entre indivíduos multipertencentes, que assumem papéis flexíveis em processos de integração, suscetíveis de valorizar o potencial de riqueza e de inovação ligado a uma diferenciação incitada ou estimulada.

A estrutura pertinente possibilita aumentar a iniciativa e a inovação, cria a possibilidade de novos serviços que podem significar uma vantagem competitiva, e permite a reunião de dimensões estratégicas interdependentes e de importância equivalente (sem hierarquia).

As principais características de uma organização em rede interna seriam, para Crémadez \& Grateau (1997), as seguintes:

- A dinâmica organizacional supera (ou prevalece sobre) as formas estruturais.

- Um profissional pode ser responsável por uma dimensão da organização e subordinado ao responsável de uma outra dimensão. Esta estrutura estimula a capacidade de liderança da organização. 
- A missão da liderança formal seria mobilizar o potencial de iniciativa da organização a serviço de uma perspectiva estratégica.

- O dirigente deve se preocupar com a adesão dos atores aos eixos de colaboração. A desierarquização da participação nas instâncias de integração é um imperativo.

- Em uma estrutura em rede, a estratégia e as opções em geral são elaboradas em conjunto, em uma perspectiva global.

- O Poder se fundamenta na capacidade de fazer chegar a informação aos indivíduos que estão melhor localizados para utilizá-la, sem retê-la.

- A solidariedade predomina, o desempenho é coletivo.

- Os processos são de auto-organização.

- Não se deve descurar da ambiência externa, que é o perigo implícito na excessiva preocupação com as relações internas.

Uma Rede estaria composta por pólos (nós da rede) que combinam as unidades de base em função de conexões que visam a obter a integração desejada. Estas conexões podem corresponder estruturalmente a comitês permanentes ou temporários ou a departamentos e podem se dar em vários planos: conexões econômicas, burocráticas, operacionais, culturais etc., várias dimensões podem estar presentes simultaneamente.

Em relação ao poder de ativação, de criação de novos intercâmbios, de novas conexões, defende-se um modo de ativação controlada: grande efervescência na base, limitada por processos de seleção de iniciativas na cúpula.

O conjunto do dispositivo estaria baseado no principio da auto-organização das relações entre as unidades, que se desenvolve nos pólos de integração, e da auto-organização das unidades de base, correspondendo a um modelo de descentralização, que é mais amplo na medida em que as unidades são de pequeno tamanho e que a organização é plana, achatada. A capacidade de representação nas estruturas de integração estaria baseada na competência relacionada à problemática tratada e não na linha hierárquica (na chefia tradicional).

O enfoque sugere a possibilidade de vários critérios de definição de eixos transversais: população (idosos, mãe-filho...), conjunto de patologias (cancerologia, endocrinologia), campo anatômico (visceral, neurológico), implementação de tecnologias mais ou menos sofisticadas (cirurgia, transplantes).

Em relação a este último aspecto, algumas técnicas permitiriam uma estrutura de tratamento multidisciplinar, como por exemplo (Le Ludec, 1995a apud Rivera, 1998): reagrupamento em torno das técnicas laser de gastroenterologistas, dermatologistas, ginecologistas e cirurgiões; reagrupamento de fisiologistas, radiologistas e neurologistas em torno da ecografia vascular; reunião em torno 
da cirurgia anti-arrítmica de cardiologistas, cirurgiões cardiovasculares, engenheiros biomédicos.

Trata-se, portanto, de mobilizar as sinergias ao redor de aproximações multidisciplinares, da problemática das emergências, dos idosos etc. Ou seja, de superar a rígida atomização entre as unidades de base correspondentes às tradicionais especialidades médicas, procurando articulá-las a partir dos critérios anteriores, considerados em um sentido abrangente. Particular importância concede-se, ainda, ao critério gerencial: tipo de atendimento neste processo de desatomização.

O objetivo central da estrutura em rede é desenvolver redes de reflexão estratégica. As conexões variam. Algumas são importantes estrategicamente, mas não geram ligações operacionais pesadas e contínuas.

Quando o campo transversal das relações aumenta (muitas unidades de base contempladas), a densidade das relações operacionais diminui, o que enseja uma centralização vertical na dimensão estratégica e uma descentralização horizontal importante. Isto corresponde a um contexto organizacional em que várias unidades seguem diretrizes estratégicas comuns com grande autonomia operacional.

$\mathrm{Na}$ busca pela transversalidade, o enfoque faz justiça ao critério gerencial como potencial fator de integração ou de reunião da diversidade. Sustenta-se a necessidade de explorar as formas ou modos de atendimento (ambulatório, hospital-dia, emergências etc.) como lugares possíveis de negociação interdisciplinar. Esta forma de gerenciamento defende a necessidade de normalizar os modos de atendimento para organizar a diversidade, como veremos adiante. Esta normalização implicaria a definição comunicativa das características dos processos de trabalho respectivos e de suas condições de sucesso ou, dito de outro modo, no estabelecimento de diálogos internos voltados para a geração de acordos sobre estas variáveis das formas de atendimento. Esta definição daria subsídios complementares para uma política de maior adaptação do perfil dos recursos humanos.

Este método de gerenciamento assume a necessidade de questionar a rigidez organizacional, promovendo a mobilidade e a polivalência e de planejar melhor a alocação de recursos humanos, tendo em vista o grau de adaptação dos mesmos às necessidades tecnológicas do trabalho e suas expectativas de satisfação. Assim, a gestão de recursos humanos é vista pelo enfoque como lugar dinâmico de definição das qualidades relativas ao perfil dos recursos que cada forma de atendimento demandaria e de suas possibilidades de satisfação. Da mesma maneira que em relação ao uso da categoria modo de atendimento como possibilidade de diálogo normalizador a serviço da transversalidade, o enfoque assume a gestão de recursos humanos como uma um grande locus de reflexão estratégica sobre a motivação dos profissionais (recursos humanos), para além da especialização, como será desenvolvido mais adiante. 


\section{A Organização da Diversidade ao Redor do Conceito de Modo de Atendimento}

Crémadez e Grateau (1997) partem da premissa de que a evolução tecnológica acarreta vários fenômenos em boa parte articulados: uma diversificação importante dos modos de atendimento; o compartilhamento crescente das infra-estruturas por distintos tipos de profissionais; uma interdependência crescente entre as unidades clínicas e logísticas; a oferta direta por parte das estruturas técnicas de apoio diagnóstico e terapêutico de prestações específicas. Estes fenômenos correspondem, em geral, à dissociação crescente da atividade clínica das infra-estruturas dentro das quais ela se exerce (ela deixa de ser exercida em um único lugar). Isto multiplica e torna mais complexos os processos de trabalho, as combinações de processos e os lugares e condições de exercício profissional,

De territórios quase privados, as unidades de cuidados transformam-se em ferramentas compartilhadas, em tipos de estruturas técnicas cada vez mais diferenciadas, que oferecem aos profissionais e aos pacientes recursos adaptados a uma concepção mais variada e mais aberta das práticas de cuidados.

Há, por conseguinte, uma diversificação crescente dos processos de atenção e, paradoxalmente, um aumento do grau de interdependência dos mesmos e das várias atividades que compõem a cadeia de valor de cada um. A necessidade de uma maior interdependência se expressa tanto no interior de cada hospital quanto entre ele e a rede.

Uma diversidade crescente de atores é mobilizada pelos processos de trabalho, em função de seu caráter cada vez mais transversal. Diante deste panorama, surge a necessidade de um trabalho de gestão da diversidade, de análise e otimização de processos, que possa operar como potente alavanca de comunicação e de compreensão entre os atores envolvidos, e de eficácia, vista pelo lado do controle da qualidade e dos custos. Preocupados com a necessidade de racionalizar o trabalho no interior dos hospitais, Crémadez e Grateau sugerem a proposta de tentar reduzir a diversidade de processos de produção de cuidados, identificando um número limitado de processos operacionais/tipos, correspondentes a modos de atendimento aglutinadores.

O objetivo deste trabalho de gestão ou de organização da diversidade seria promover a modelização, a normalização de um número limitado de processos implementados em tantas estruturas diferentes (de serviços especializados) quanto maior seja o tamanho do estabelecimento. Esta visão, que concede um privilégio à categoria modo de atendimento, rompe com a imagem da prática médica como 
um tipo de prestação que depende fundamentalmente da tecnicidade de seus atos, da personalidade e competência dos profissionais especializados, e que se exerce através de um único modo de atendimento.

Um modo de atendimento é definido como a normalização do processo (ou o conjunto do percurso) que se faz seguir a um paciente, a fim de satisfazer a necessidade que o leva a recorrer à instituição. Um modo de atendimento caracteriza a organização do trabalho no seio da estrutura (hospital, especialidade, serviço) que se dedica à sua implementação, e o tipo de relações que ela mantêm com as unidades prestadoras de serviço que concorrem para este atendimento. Um modo de atendimento é de alguma maneira um processo depurado das particularidades ligadas a um domínio de cuidados preciso (especialidade). Neste sentido, pode-se falar em normalização.

Os principais modos de atendimento identificados são: Hospitalização Convencional; Hospitalização Domiciliar; Consultação; Emergências; Hospitalização Programada de Duração Determinada (reunião de várias especialidades em um mesmo estabelecimento que trata de eventos nosológicos programáveis) etc.

O principal objetivo desta modelização é ajudar à gestão operacional, na medida em que permite padronizar e controlar processos produtivos, com mais qualidade e eficiência, e adequar os recursos (especialmente, os recursos humanos) aos mesmos. Esta normalização ajuda aos prestadores logísticos a adaptar seus serviços às características de cada modelo de atendimento e permite, ainda, definir os níveis de exigência que cada um deles deveria atender para obter uma vantagem comparativa.

Os autores sugerem uma proposta de leitura e de análise destes modelos, constituída de variáveis que permitem identificar as características de cada modo de atenção, e de variáveis que correspondem a fatores determinantes de seu desempenho, como veremos a seguir (Figura 6).

Estas variáveis permitem diagramar os vários modos de atendimento e compará-los. Esta diagramação implica a atribuição por consenso de valores de zero a 4 às dimensões e aos fatores abrangidos pelas variáveis, em função de sua importância relativa para cada modo de atendimento. Apresentaremos dois diagramas correspondentes à emergência e à hospitalização programada de duração determinada (HPDD), considerando os dois tipos de variáveis apontadas (figuras 7 e 8 ). 
Figura 6 - Caracterização de tipos de atendimento.

\begin{tabular}{|l|l|}
\hline \multicolumn{1}{|c|}{$\begin{array}{c}\text { Características dos processos } \\
\text { implementados }\end{array}$} & \multicolumn{1}{c|}{ Comentários } \\
\hline $\begin{array}{l}\text { Parâmetros de Concepção } \\
\text { Controle do tempo } \\
\text { Flexibilidade } \\
\text { Polivalência }\end{array}$ & $\begin{array}{l}\text { Em que medida esta dimensão é considerada? } \\
\text { Há necessidade de se adaptar? } \\
\text { Qual o grau de heterogeneidade das atividades? }\end{array}$ \\
\hline $\begin{array}{l}\text { Nível de Complexidade } \\
\text { Sofisticação técnica } \\
\text { Multiplicidade de intervenientes } \\
\text { Variantes }\end{array}$ & $\begin{array}{l}\text { Grau de sofisticação dos atos praticados? } \\
\text { Os intervenientes são numerosos? }\end{array}$ \\
\hline $\begin{array}{l}\text { Modo de Regulação-Chave } \\
\text { Formalização/Padronização } \\
\text { Ajustamento mútuo entre atores } \\
\text { Programação }\end{array}$ & $\begin{array}{l}\text { Os procedimentos são codificados? } \\
\text { As relações entre atores são densas? }\end{array}$ \\
\hline $\begin{array}{l}\text { Eapacidade de Adaptação } \text { necessário o planejamento? } \\
\text { Descontinuidade } \\
\text { Imprevisto } \\
\text { Incerteza }\end{array}$ & $\begin{array}{l}\text { A variabilidade dos fluxos é fundamental? } \\
\text { O imprevisto é inerente ao modo x ? }\end{array}$ \\
\hline $\begin{array}{l}\text { Atitude-Chave } \\
\text { Proatividade } \\
\text { Reatividade } \\
\text { Seletividade }\end{array}$ & O atendimento é adaptável no processo? \\
\hline
\end{tabular}

\begin{tabular}{|l|l|}
\hline \multicolumn{1}{|c|}{$\begin{array}{c}\text { Fatores determinantes do } \\
\text { desempenho }\end{array}$} & \multicolumn{1}{c|}{ Comentários } \\
\hline $\begin{array}{l}\text { Relação com o Tempo } \\
\text { Observância dos prazos } \\
\text { Dspera }\end{array}$ & $\begin{array}{l}\text { Em que medida a satisfação do paciente } \\
\text { depende da observância de cada um dos } \\
\text { critérios que qualificam a relação com o } \\
\text { tempo característica do modo estudado? }\end{array}$ \\
\hline $\begin{array}{l}\text { Regulação das Interfaces } \\
\text { Antes }\end{array}$ & $\begin{array}{l}\text { Em que medida a qualidade das prestações é } \\
\text { função do controle do que ocorre antes, } \\
\text { durante e depois da hospitalização? }\end{array}$ \\
Depois & $\begin{array}{l}\text { Em que medida a qualidade das prestações } \\
\text { desses tipos influi sobre a satisfação do } \\
\text { paciente? }\end{array}$ \\
\hline $\begin{array}{l}\text { Médicas } \\
\text { Admínticas }\end{array}$ & $\begin{array}{l}\text { Em que medida a qualidade da colaboração } \\
\text { nos três níveis de organização do hospital } \\
\text { influi sobre a qualidade da prestação e sobre a } \\
\text { satisfação do cliente? }\end{array}$ \\
\hline $\begin{array}{l}\text { Integração } \\
\text { Na equipe de base } \\
\text { Com atores complementares } \\
\text { Com outras unidades }\end{array}$ & $\begin{array}{l}\text { Em que medida a qualidade da prestação é } \\
\text { determinada por uma descrição precisa do } \\
\text { campo de ação coberto pelo modo de } \\
\text { atendimento (quem, por que, como?) }\end{array}$ \\
\hline $\begin{array}{l}\text { Formalização } \\
\text { Modo de seleção } \\
\text { Protocolos clínicos } \\
\text { Processos de atendimento }\end{array}$ & \\
\hline
\end{tabular}


Figura 7 - Comparação das características de dois modos de atendimento.

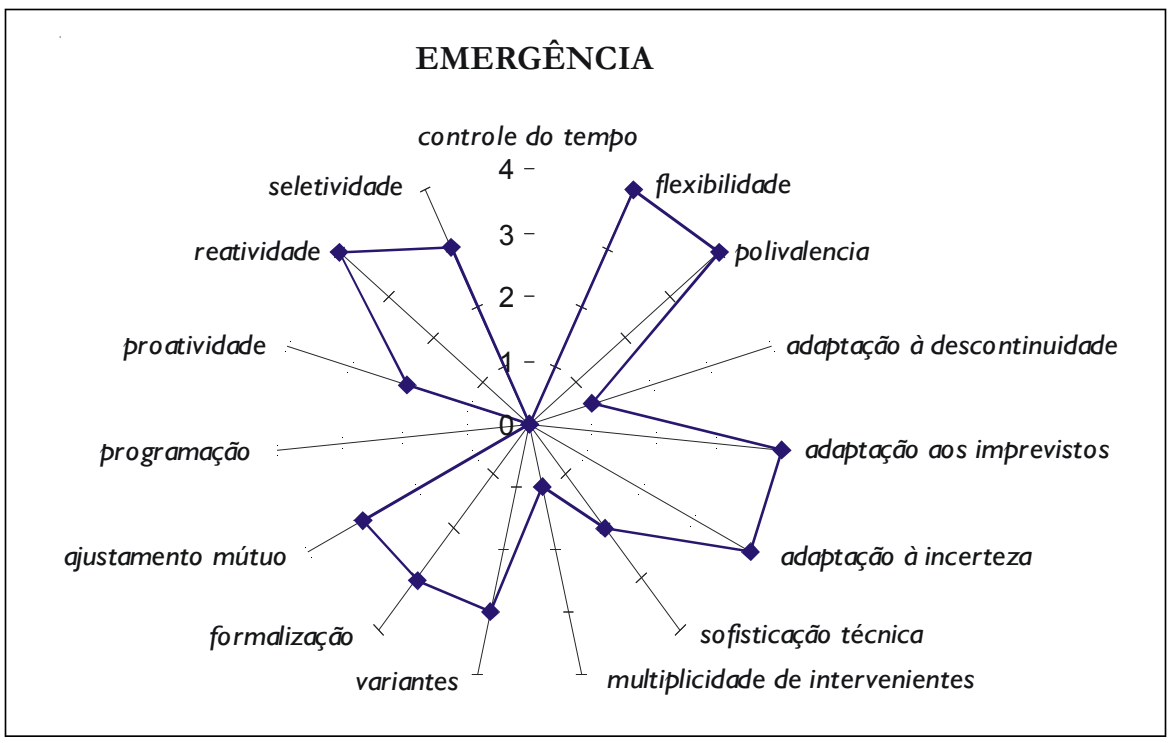

\section{HOSPITALIZAÇÃO PROGRAMADA DE DURAÇÃO DETERMINADA}

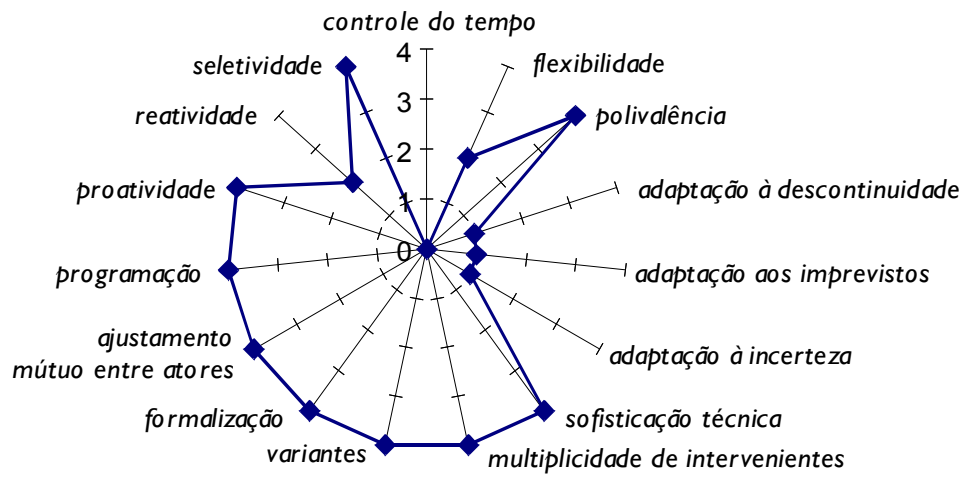


Figura 8 - Comparação dos fatores determinantes do desempenho.

\section{EMERGÊNCIA}

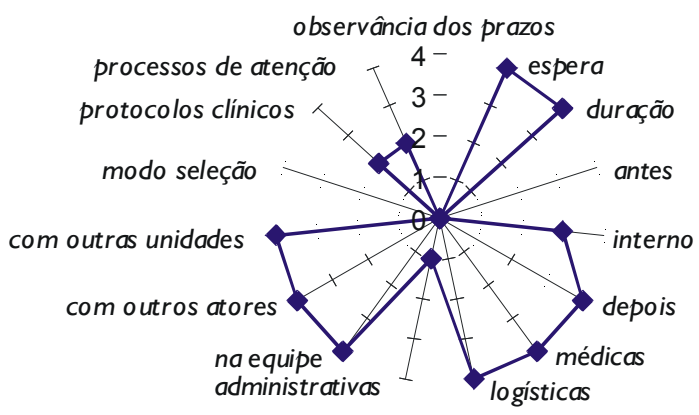

\section{HOSPITALIZAÇÃO PROGRAMADA DE DURAÇÃO DETERMINADA}

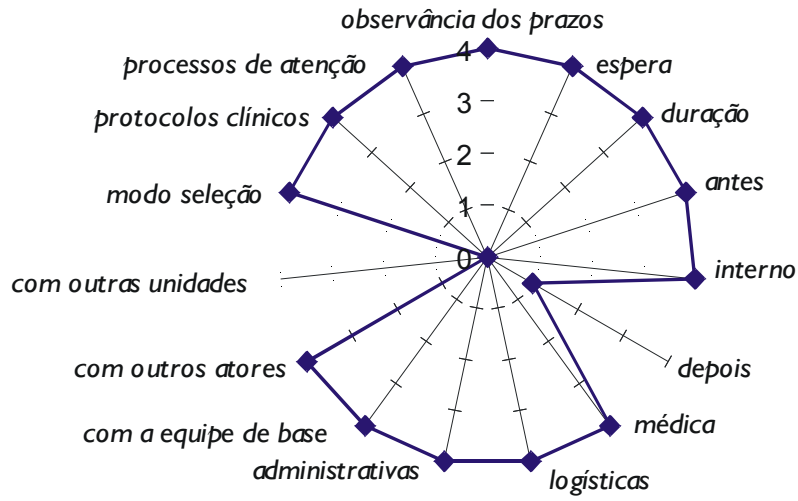


A análise comparativa dos dois modos revela que, do ponto de vista dos fatores determinantes da satisfação, a HPDD é muito mais exigente, considerando-se as possibilidades de obtenção de vantagens comparativas. Ela é altamente sensível a todos os critérios, ao passo que o outro é sensível apenas alguns. Para que o modo HPDD seja bem-sucedido, deve responder de maneira satisfatória ao nível de exigência requerido. Questões como a observância dos prazos, o controle do desempenho administrativo e uma maior padronização de procedimentos são fatores claramente distintivos.

Os dois modos respondem a necessidades diferentes. Isto significa que cada vez que se atenda na emergência um paciente que se beneficiaria mais de uma HPDD, gerar-se-á uma satisfação menor e serão aceitas disfunções que colocarão a instituição em uma posição vulnerável por referência a um concorrente capaz de oferecer um atendimento adaptado.

Uma modelização deste tipo permitiria:

- Encaminhar os pacientes aos modos de atendimento suscetíveis de aumentar sua satisfação.

- Limitar as disfunções ligadas à inadaptação dos processos e das estruturas à diversificação das necessidades.

- Oferecer novas fontes de satisfação aos recursos humanos.

No entanto, a idéia central desta aproximação é permitir a gestação de um diálogo entre profissionais de distintas especialidades em torno de critérios gerenciais, definidos pelos modelos de atendimento apontados. Este processo de comunicação (de alcance progressivamente crescente), visaria a estruturar uma linguagem ou um glossário comum, desenvolver uma capacidade de concepção operacional, capaz de aglutinar, de integrar, de permitir contatos interdisciplinares (Rivera, 1998).

Toda a prática da démarche estratégica objetiva, fundamentalmente, a busca da integração como alternativa à diferenciação das organizações profissionais, resgatando o traço cultural da autonomia, o que significa apostar em processos de gestão ascendentes. Mesmo referindo-se à segmentação estratégica (definição dos produtos das especialidades hospitalares em termos de agrupamentos homogêneos de atividades), esta preocupação está presente: a busca da transversalidade problemática, das sinergias operacionais e culturais.

$\mathrm{Na}$ prática, o resgate do componente gerencial tipo ou modo de atendimento como fenômeno aglutinador introduz una nova forma de transversalidade, que se soma aos critérios população, tecnologia, conjunto de patologias etc. (da segmentação estratégica), que permitiria adensar o campo das possibilidades de estruturas em rede interna (Rivera, 1998). 
Como afirmam os autores (Crémadez \& Grateau, 1997:395):

Depuis quelques anneés, la diversité s'impose progressivement à l'hôpital, sans qu'il soit preparé à l'assumer, ce qui provoque un certain nombre des convulsions dont nous sommes témoins actuallement. Pour y faire face, il lui faut adapter sa culture e ses modes d' action et être capable de plus de formalization pour faciliter la communication qui devient une variable déterminante de l'efficacité en permettant à l'efficience des différents professionnels de mieux se conjuguer. Mais il lui faut aussi apprendre à standardiser ses pratiques sans les uniformizer et sans perdre la flexibilité et l'adaptabilité que lui confere sa caractéristique de structure organique.

A organização da diversidade, coerentemente com a referência, comporta um duplo movimento: normalização-diferenciação. A modelização dos modos de atendimento, em função dos processos abrangidos, suporia o movimento contrário: a adaptação dessa modelização geral ao contexto organizacional específico dos profissionais que organizam suas práticas em função da população específica que atendem, das patologias pertinentes e das tecnologias ad-hoc do serviço.

\section{A Gestão de Recursos Humanos como Interação em Busca da Flexibilidade e da Motivação}

O enfoque estratégico em pauta se propõe a questionar a rigidez organizacional, expressa do ponto de vista dos recursos humanos por dois fenômenos: a falta de mobilidade profissional e a inexistência de uma política de planejamento e de gestão operativa desses recursos, apoiada na busca de uma adaptação entre as exigências de qualidade (de perfil) e as fontes de satisfação implícitas nos processos de trabalho, de um lado, e a alocação de recursos profissionais, de outro.

A alocação de recursos humanos segue, predominantemente, uma via hierárquica, caracterizada pela predominância do critério tecnocrático da especialidade e da disciplina médica, não considerando o critério gerencial da diversidade de formas de prática que uma mesma especialidade pode assumir. Para além da consideração exclusiva das competências técnicas individuais, os autores analisados propõem a necessidade de uma nova concepção de carreiras, horizontal, fundamentada na diversidade de condições de exercício das (mesmas) competências profissionais no hospital.

Neste sentido, eles se apóiam no conceito já analisado de modo de atendimento. Cada um dos modos ou tipos de atendimento identificados corresponde 
a uma "situação profissional", representa uma faceta do fazer médico. Cada um requer qualidades humanas e profissionais singulares, determina condições de trabalho e oferece fontes de satisfação específicas que concedem a um determinado fazer uma riqueza singular.

Trabalhar no centro cirúrgico, em reanimação, em um serviço de geriatria, na unidade ambulatorial de um hospital, na hospitalização domiciliar, na consultação etc. são situações profissionais que requerem aptidões, saberes específicos, competências, características psicológicas diferentes. Por outro lado, estas situações comportam fontes de satisfação e de motivação específicas. Caracterizá-las e utilizar sua riqueza e diversidade para conceber formas de encaminhamento das carreiras e uma gestão de pessoal moderna parece ser primordial. Organizar a mobilidade sobre a base do conceito de modo ou tipo de atendimento pode oferecer múltiplas formas de satisfação, novas motivações e novas perspectivas de evolução para os indivíduos.

Pode-se praticar um exercício análogo ao que foi feito em relação à diferenciação dos modos de atendimento. Basicamente, dois quadros de variáveis podem ser construídos: um, correspondente às qualidades requeridas (em termos de perfil profissional) por cada forma, e outro, representado pelas fontes de satisfação (figuras 9 e 10). Exemplos:

Figura 9 - Exemplos de qualidades requeridas.

\begin{tabular}{|c|c|}
\hline Qualidades requeridas & Comentários \\
\hline $\begin{array}{l}\text { Competências Profissionais } \\
\text { Técnica } \\
\text { Pedagógica } \\
\text { Atualização }\end{array}$ & $\begin{array}{l}\text { Nível de tecnicidade requerido } \\
\text { Exigências de educação dos pacientes } \\
\text { Necessidade de renovar conhecimentos e práticas }\end{array}$ \\
\hline $\begin{array}{l}\text { Aptidões Pessoais } \\
\text { Aptidão de concepção } \\
\text { Aptidão decisional } \\
\text { Aptidão relacional }\end{array}$ & $\begin{array}{l}\text { Conceber e organizar o atendimento } \\
\text { Decidir frente a situações imprevistas } \\
\text { Abrir-se ao próximo e comunicar-se }\end{array}$ \\
\hline $\begin{array}{l}\text { Capacidades de Ação Coletiva } \\
\text { Auto-organização } \\
\text { Trabalho em equipe } \\
\text { Gestão de parcerias }\end{array}$ & $\begin{array}{l}\text { Organização pessoal, método e rigor } \\
\text { Inserção grupal, contribuição ao trabalho } \\
\text { coletivo } \\
\text { Autoridade e senso da negociação }\end{array}$ \\
\hline
\end{tabular}


Figura 10 - Exemplos de fontes de satisfação.

\begin{tabular}{|c|c|}
\hline Fontes de satisfação & Comentários \\
\hline Inserção profissional & $\begin{array}{l}\text { Reconhecimento no seio de um grupo, sentimento } \\
\text { de pertença }\end{array}$ \\
\hline Responsabilidade & Engajamento e capacidade de iniciativa \\
\hline Valorização técnica & Sofisticação das práticas profissionais \\
\hline Carga afetiva & Implicação e sentimento de utilidade Facilidade no \\
\hline Controle da relação com o outro & relacionamento interpessoal \\
\hline Autonomia & Liberdade de ação \\
\hline
\end{tabular}

Estes quadros de variáveis nos permitem estabelecer vários diagramas referentes aos vários tipos de atendimento, onde se procura identificar o nível de exigência de cada variável e o grau de envolvimento dos fatores de motivação assinalados em cada modo específico. Para simplificar e considerando que este trabalho é apenas uma introdução ao tema, apresentaremos os casos da hospitalização convencional e da hospitalização domiciliar (Figura 11).

Figura 11 - Comparação das situações hospitalar e extra-hospitalar.

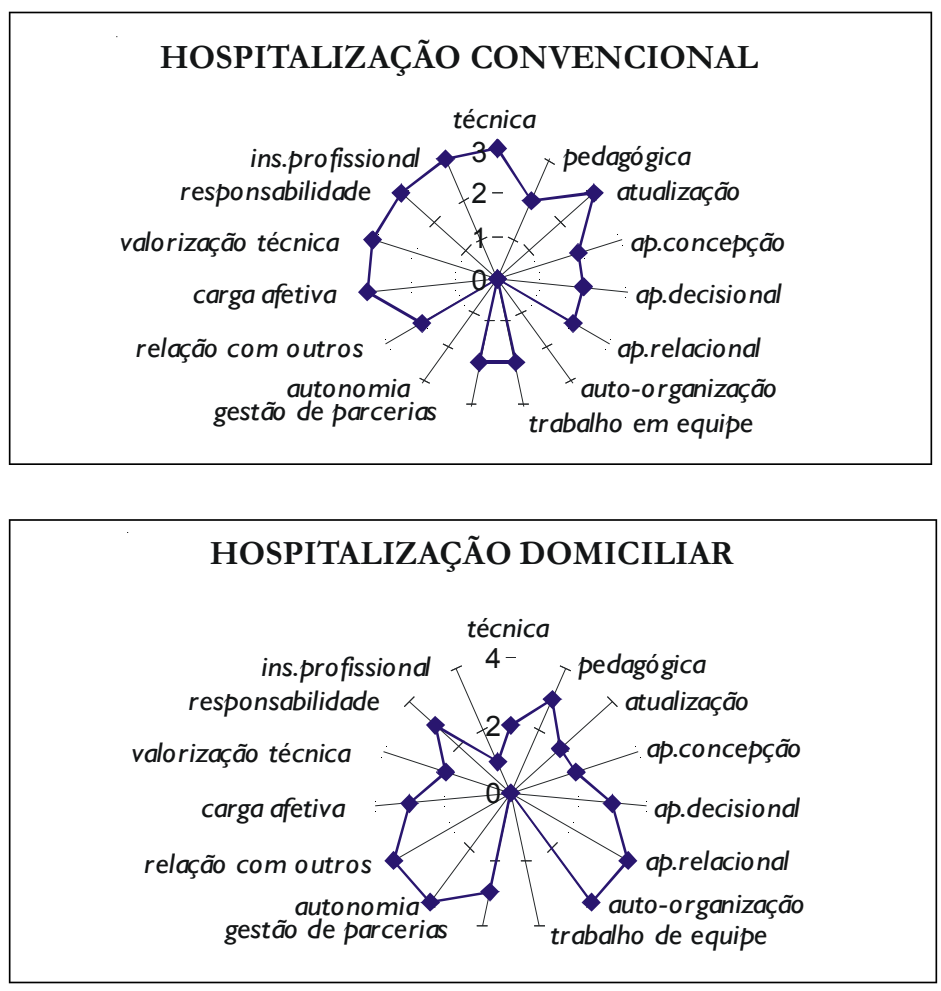


Assim, trabalhar em uma hospitalização em domicílio pode fazer da capacidade de auto-organização um elemento-chave, ao passo que esta apresentará somente um interesse mínimo em um contexto sedentário e estruturado como a hospitalização convencional, que requererá capacidades de trabalho em equipe mas menos desenvolvidas que em uma unidade de tratamento de emergência.

Trabalhar em consultação demandaria menos, no plano das competências técnicas, do que trabalhar na perspectiva da hospitalização programada de duração determinada. Porém, a exigência de atualização técnica não é fundamentalmente diferente. A atitude de concepção seria, no caso da consultação, menos solicitada do que a atitude decisional.

A análise das qualidades requeridas, combinadas com a análise das características e dos fatores de desempenho de um tipo de atendimento permite compreender melhor o clima organizacional, a pressão exercida sobre os indivíduos e apreciar melhor a natureza da atração que ele pode representar (ou não) para os profissionais segundo sua idade, sua motivação, seus antecedentes, assim como seu contexto social. Assim claramente explicitados, os modos ou tipos de atendimento podem permitir a um agente se projetar em um percurso profissional, e à instituição negociá-lo em função de seu perfil e de sua evolução e dos meios que ela pode mobilizar para favorecer num ou noutro sentido profissional.

A partir de uma análise multicritérios, obtêm-se representações dos diferentes tipos de atendimento. $\mathrm{O}$ resultado deste exercício praticado por um grupo profissional homogêneo nos mostra que, para seus membros, a satisfação fornecida pela HPDD está mais ligada à técnica e ao trabalho em equipe enquanto que para a hospitalização domiciliar são os aspectos relacionais e a autonomia que importam. Que a emergência comporta uma carga afetiva bem superior à consultação ou à HPDD.

O exemplo citado pode parecer caricatural, mas é ilustrativo. O que importa é explorar as possibilidades de uma tal aproximação, para o que seria necessário: dispor de um número maior de critérios, cuja definição precisa constituirá um glossário; selecionar e definir os critérios com as pessoas envolvidas (o caráter participativo é essencial); e estabelecer com elas as representações dos vários tipos de atendimento. Devem-se estabelecer e confrontar. A representação que cada grupo profissional tem das características e da atratividade de cada tipo de atendimento, de um lado, e a representação que deles podem ter as equipes de base que os implementam, do outro.

Esta aproximação não deve ser encarada mecanicamente. Trata-se de gerar um diálogo, de providenciar ferramentas úteis aos profissionais para melhor compreender e melhor adaptar-se ao seu universo profissional, inovar e fazê-lo evoluir. Busca-se uma melhor adequação entre indivíduos e organização em uma perspectiva dinâmica, permitindo lhes libertar-se justamente das representações 
caricaturais e ajudando-os a operar as evoluções desejáveis para eles e para a organização onde exercem.

A aproximação anterior pode ter várias aplicações. Uma delas é conceber modalidades de avaliação da carga de trabalho e de determinação do efetivo mais pertinente: assim, a avaliação poderá ser realizada de maneira diferente no caso de uma hospitalização convencional - em que a clientela é mais heterogênea, o serviço, menos codificado, menos formalizado e o tempo, menos restritivo - e no de uma HPDD que fornece serviços de uma variedade limitada e conhecida, a uma clientela selecionada, em um quadro temporal mais restritivo em termos de prazos e de cronologia.

Adaptar os horários e o tempo de trabalho é outra das aplicações: os ritmos de trabalho e os horários poderão ser diferenciados segundo a necessidade de continuidade no atendimento ou ao contrário a ausência de continuidade, mas também segundo a distribuição dos fluxos de pacientes, a importância dos fatores aleatórios ou o controle quantitativo da atividade pela programação.

Por fim, deve-se lembrar de adaptar os indicadores de desempenho individual e fazer emergir a noção de desempenho coletivo. A observância dos prazos predominará em certos casos sobre a duração, a densidade (complexidade) dos pacientes sobre o número.

Mas também, organizar a mobilidade e a polivalência no hospital e conceber os planos de formação conciliando as necessidades institucionais, as necessidades profissionais e as expectativas individuais. A identificação dos tipos de atendimento permite esclarecer aos indivíduos as diferentes possibilidades de exercício profissional que a instituição lhes oferece e explicitar suas características, seus desafios, exigências e vantagens. Uma primeira diferenciação de perfis profissionais está dada pelo conceito de modo ou tipo de atendimento normalizado. Uma segunda diferenciação deverá ser feita no sentido da definição das especificidades existentes no nível de cada tipo de atendimento, especificidades ligadas às exigências particulares das populações e das especialidades médicas. Esta segunda revelará toda a variedade do exercício de cada profissão representada no hospital. A diferenciação de perfis, feita nas duas bases, permitiria oferecer um quadro geral de ajuda à detecção das possibilidades de mudança para os interessados mesmos e para a organização. Esta identificação pressuporia o confronto entre as possibilidades de perfil profissional implícitas nos processos de trabalho e as características específicas dos recursos humanos, aferidas através de processos de avaliação dos mesmos (Figura 12), em que se procuraria levantar em que medida determinadas exigências de perfil profissional são por eles preenchidas. A questão está em saber em que medida determinadas exigências representam pontos fortes ou fracos para um determinado recurso humano. 
Figura 12 - Elementos da avaliação.

\begin{tabular}{|l|l|l|}
\hline $\begin{array}{c}\text { Competências } \\
\text { profissionais }\end{array}$ & Pontos fortes & Pontos fracos \\
\hline $\begin{array}{l}\text { Técnica } \\
1\end{array}$ & & \\
$3 . \ldots \ldots .$. & & \\
\hline Pedagógica & & \\
\hline$\ldots \ldots \ldots \ldots \ldots \ldots . .$. & & \\
\hline Atualização & & \\
\hline
\end{tabular}

Elementos de um balanço de competências (1, 2, 3 etc.corresponderiam a critérios específicos de cada competência que permitiriam qualificá-la melhor).

O objetivo de gerar a mobilidade é oferecer, aos profissionais, a possibilidade de renovar a sua motivação. E do ponto de vista da instituição, permitir uma alocação de recursos humanos mais flexível, que responda às necessidades de curto e longo prazo e mais adaptável, no sentido de um planejamento de RH que leve em conta a evolução da tecnologia e das necessidades. Neste último caso, o componente prospectivo é essencial e pode se manifestar por exemplo através da necessidade de um reequilíbrio entre formas de atendimento (redução relativa da hospitalização tradicional em beneficio da HPDD) ou através da emergência de novas formas de atendimento, como o campo da psiquiatria vem a gerar a partir do momento em que ela decide por sua externalização.

A busca por uma maior flexibilidade e de uma maior adaptabilidade supõe um movimento inverso àquele realizado no sentido de captar a diferenciação que define toda a riqueza do exercício profissional em um hospital. Aumentar a flexibilidade operacional significa definir um marco para organizar a desatomização, os intercâmbios de experiência, as substituições, as equipes de plantonistas, etc. Trata-se de recompor a diversidade buscando não mais os fatores de diferenciação mas os fatores de integração, as proximidades de quaisquer tipos. Os modos ou tipos de atendimento são evidentemente o primeiro nível desta recomposição. Mas pode-se ir além e buscar as similitudes entre modos de atendimento. Os grupos de polivalência assim constituídos permitirão ampliar as possibilidades de gestão qualitativa e quantitativa.

Um grupo de polivalência será constituído, seja por uma reaproximação de tipos de atendimento que valorize características comuns a cada um dos modos reagrupados seja por um reagrupamento de perfis diferenciados cuja proximi- 
dade terá sido julgada sobre um critério diferente (população, patologia, tecnologia). A proximidade deverá ser suficiente para que os profissionais possam revezar-se (mediante um curto prazo de adaptação derivado de uma formação).

Tal forma de gestão das competências dos RH baseada no critério gerencial tipo de atenção, para além do critério técnico da especialidade médica, tem o grande mérito de ser uma forma de gestão que não busca a adequação entre o indivíduo e um posto de trabalho ou que não opera sobre a base da descrição de tarefas a realizar. Ela busca analisar a adequação dos indivíduos a contextos de ação amplos, definidos sob o ângulo organizacional (as relações entre os diferentes atores), sob o ângulo pessoal (as qualidades e motivações individuais) e sob o ângulo estratégico (a qualidade do serviço a fornecer). Desta maneira, busca-se uma aumento global da competência institucional, para além das competências individuais e técnicas. Dada a natureza participativa desta gestão, o que se valoriza são essencialmente as capacidades de auto-organização das unidades e lugares de trabalho.

Uma proposta deste tipo supõe uma nova forma de encarar a formação. A formação deveria estar subordinada aos objetivos institucionais e privilegiar uma concepção mais ampla da eficácia, que implicasse na possibilidade de que os vários atores venham a perceber as interações que condicionam o desempenho global da organização. O desafio é integrar as competências pessoais e profissionais em um quadro coletivo de funcionamento.

Uma proposta nova de formação deveria integrar três dimensões: a das competências necessárias a cada um dos grupos profissionais que compõem o hospital, centradas no conjunto: disciplinas, especialidades e grupos de tecnologias/patologias; a das interações entre profissionais, que caracterizam o modo de funcionamento operacional das unidades de base e os processos implementados; a das relações entre grupos profissionais que condiciona o funcionamento global da organização através do jogo das relações hierárquicas, e das relações logística-tecnoestrutura-centro operacional.

A cada um destes campos corresponderia um tratamento apropriado da formação que permita realizar o indispensável duplo movimento de diferenciação e de integração. Diferenciação pela posta em prática de ações que permitam dotar cada grupo profissional das competências específicas necessárias à boa realização de seu papel, integração pela implementação de ações que permitam aos diferentes profissionais, convocados a colaborar, um melhor controle das condições de sua colaboração. Cada um destes campos está caracterizado por um determinado mix profissional e de conteúdos de formação específicos: dominante técnica para o primeiro, dominante relacional para o segundo, dominante gerencial para o terceiro. $\mathrm{O}$ interesse por este tipo de proposta de formação depende de sua associação a uma renovação da concepção de carreiras de pessoal e à valorização da formação continuada como ferramenta de formação profissional. 


\section{Referências Bibliográficas}

ARTMANN, E. Démarche Stratégique (Gestão Estratégica Hospitalar): um enfoque que busca a mudança através da comunicação e solidariedade em rede, 2002. Tese de Doutorado, Campinas: Departamento de Medicina Preventiva da Faculdade de Ciências Médicas, Unicamp.

CRÉMADEZ, M. \& GRATEAU, F., 1992 (1ª ed.), 1997(2ªed.). Le Management Stratégique Hospitalier. Paris: Inter Éditions.

CROZIER, M. \& FRIEDBERG, E. L'Acteur et le Système. Paris: Éditions du Seuil, 1977.

LAWRENCE, P. R. \& LORSCH, J. H. Adapter les Structures de l'Entreprise. Éditions d'Organisation, 1973.

LE-LUDEC, T. L'Autonomie Stratégique des Établissements de Santé: Frein ou Levier pour la Régulation du Système Hospitalier? Actes du Colloque de la Société Française d'Évaluation des Stratégies. Montpellier, 1995.

MINTZBERG, H. Structure et Dynamique des Organisations. Paris: Éditions d'Organisation, 1982.

PORTER, M. E. Choix Stratégiques et Concurrence. Paris: Ed. Econômica, 1982.

RIVERA, F. J. U. A “démarche” estratégica: a metodologia de gestão do Centro Hospitalar Universitário de Lille, França. Cadernos de Saúde Pública, 13(1):73-80,jan/mar., 1997.

RIVERA, F. J. U. O enfoque de integração estratégica de Crémadez e Grateau e a gestão de recursos tecnológicos e humanos. RAP 32(6):179-208, 1998.

STRATEGOR, Stratégie, Structure, Décision, Identité. Politique Générale d'Entreprise. Paris: Dunod, 1997.

THÉVENET, M., 1986. Audit de la Culture d'Entreprise. Paris: Éditions d'Organization.

UAS-CHRU (Unité d'Analyse Stratégique - Centre Hospitalaire Régional Universitaire), 1995a. La Démarche Stratégique. Guide Méthodologique. Material Instrucional. Lille: UAS-CHRU. (Mimeo.)

UAS-CHRU (Unité d'Analyse Stratégique - Centre Hospitalaire Régional Universitaire), 1995b. La Démarche Stratégique. Sommaire. Material Instrucional. Lille: UAS-CHRU. (Mimeo.) 